\title{
Concienciación juvenil frente al COVID-19 en España y Latinoamérica: análisis de spots en YouTube
}

\author{
Youth awareness against COVID-19 in Spain and Latin America: \\ analysis of spots on YouTube
}

Dra. María Esther del-Moral-Pérez. Universidad de Oviedo. España.

emoral@uniovi.es

$[\mathrm{CV}]$ (1) $\mathrm{R}$

Dra. María del Carmen Bellver-Moreno. Universidad de Valencia. España.

m.carmen.bellver@uv.es

$[\underline{\mathrm{CV}}]$ (1) G $\mathrm{C}$

Dra. Alba Patricia Guzmán-Duque. Unidades Tecnológicas de Santander. Colombia.

aguzman@correo.uts.edu.co

$[\underline{\mathrm{CV}}]$ (1) G $\mathrm{R}$

Nerea López-Bouzas. Universidad de Oviedo. España.

UO257373@uniovi.es

$[\mathrm{CV}] \bigcirc \mathrm{G} \mathbf{0}$

Cómo citar este artículo / Referencia normalizada

Del Moral-Pérez, M.E., Bellver-Moreno, M. C., Guzmán-Duque, A. P. y López-Bouzas, N. (2021). Concienciación juvenil frente al COVID-19 en España y Latinoamérica: análisis de spots en YouTube. Revista Latina de Comunicación Social, 79, 23-49. https://www.doi.org/10.4185/RLCS-2021-1510

\section{RESUMEN}

Introducción. Las consecuencias socio-sanitarias y económicas del COVID-19 llevó a los países a adoptar estrategias comunicativas de carácter preventivo, que difundieron en medios sociales para amplificar su difusión. Esta investigación analiza spots del contexto español y latinoamericano $(\mathrm{N}=100)$ orientados a concienciar a los jóvenes frente al COVID-19 publicados durante el periodo de 1 septiembre 2020 a 10 enero 2021 y accesibles en YouTube. Metodología. La metodología es mixta: cualitativa, se analizan variables comunicativas, técnico-narrativas y afectivo-emocionales; y cuantitativa, con análisis descriptivo de los datos y posterior análisis de varianza para identificar las diferencias entre ambos contextos. Resultados. El 69\% de los spots interpela a los jóvenes magnificando el riesgo, el $49 \%$ favorece su identificación, un $33 \%$ invita a la reflexión ante situaciones críticas y un $31 \%$ atemoriza con la muerte de familiares. Los spots españoles pretenden evitar reuniones/fiestas, promover el uso de mascarillas y cumplir todas las normas sanitarias, y los latinoamericanos inciden en la distancia social, hábitos de higiene y el respeto de la cuarentena. Asimismo, los españoles priorizan relatos de carácter actitudinal para modificar conductas, y los latinoamericanos priman relatos procedimentales, mostrando prácticas saludables. Ciudadanía anónima, afectados, cantantes y sanitarios de edades entre 18-35 años protagonizan los spots españoles, mientras que en los latinoamericanos son comunicadores, futbolistas o personajes conocidos de entre 35-65 años. Conclusiones. Los factores culturales compartidos entre España y 
Latinoamérica se plasman en la homogeneidad de las narrativas respecto a las variables afectivoemocionales. La representación juvenil está polarizada: se enfatizan modelos positivos o se subraya el arquetipo transgresor de normas.

PALABRAS CLAVE: YouTube; COVID-19; jóvenes audiencias; spot; medidas de prevención; publicidad; salud.

\begin{abstract}
Introduction. The socio-health and economic consequences of COVID-19 led countries to adopt preventive communication strategies, broadcasted on social media to enhance their exposure. This research examines Spanish and Latin American spots $(\mathrm{N}=100)$ that aim at raising awareness among young people about COVID-19 and that were published between 1 September 2020 and 10 January 2021 on YouTube. Methodology. The methodology is mixed: qualitative, by analysing communicative, technical-narrative and affective-emotional variables; and quantitative, with a descriptive analysis of the data followed by variance analysis to identify differences in both contents. Results. Sixty-nine percent of the spots magnify the risks, $49 \%$ foster the subjects' identification with what is being told, 33\% encourage reflection when faced with a critical situation, and $31 \%$ frighten them with the death of relatives. Spanish stories seek to avoid events/parties, promote the use of masks and comply with all health regulations. Latin American ones emphasise social distance, hygiene habits and adherence to quarantine rules. Spain prioritises attitude-based stories aimed at modifying behaviours, while Latin America prioritises procedure-based stories by showing healthy practices. Anonymous citizens, people affected by the virus, singers or health professionals, aged 18 to 35, starred in the Spanish stories, while communicators, footballers or famous personalities, aged 35 to 65, starred in the Latin American ones. Conclusions. The cultural factors shared between Spain and Latin America are reflected in the homogeneity of the narratives regarding affective-emotional variables. Youth portrayal is polarized: either positive models are emphasised, or rule-breakers are highlighted.
\end{abstract}

KEYWORDS: YouTube; COVID-19; young audiences; spot; preventive measures; advertising; health.

\title{
CONTENIDO
}

1. Introducción. 2. Campañas de concienciación juvenil y salud. 3. Objetivo. 4. Metodología. 4.1. Método. 4.2. Muestra. 4.3. Instrumento de análisis. 5. Resultados. 5.1. Variables comunicativas. 5.2. Variables técnico-narrativas. 5.3. Variables afectivo-emocionales. 6. Discusión y conclusiones. 7. Bibliografía. 8. Anexos. 9. Currículum Vitae.

\section{Introducción}

El incremento de contagios del coronavirus -detectado tras el último trimestre de 2020, y la emergencia de nuevas cepas- ha supuesto un aumento de fallecidos e infectados superando los datos iniciales de la pandemia. Por ello, la preocupación de los países por las consecuencias sociosanitarias y económicas del COVID-19 en sus poblaciones, les llevó a adoptar estrategias comunicativas audiovisuales de carácter informativo-preventivo a través de medios sociales (Castillo-Esparcia, 2020; Eghtesadi \& Florea, 2020). Sin embargo, la relajación de las conductas, derivadas del cansancio psicológico acumulado (Arias et. al, 2020; González-Casas et al., 2020; Justo-Alonso et al., 2020; Valero et al., 2020), junto a la transgresión sistemática de las normas de distanciamiento social (celebraciones familiares, fiestas clandestinas, etc.), tornaron sus campañas más agresivas (Macassi, 2020). Muchas buscaban un mayor impacto emocional para minimizar los 
contagios y apelaban a los sentimientos para concienciar de los riesgos para la salud -especialmente a los jóvenes-.

Indudablemente, las campañas institucionales de salud suponen una ocasión para informar y sensibilizar a la población, para adoptar conductas que frenen y prevengan las enfermedades. Desde la teoría psicológica de la salud, Pérez-Moedano et al. (2021) describen los modelos que subyacen en las diferentes campañas para movilizar a todas las audiencias. De forma semejante, desde una perspectiva edu-comunicacional se observan discursos de índole conceptual, ligados a la presentación de datos o explicaciones científicas sobre la trasmisión y gravedad del virus (SánchezMora, 2020). Algunos son procedimentales -próximos al conductismo social (Bandura, 1990)enumeran pautas de actuación y conductas saludables para prevenir contagios. Y, otros de carácter actitudinal (Ajzen \& Fishbein, 2000), apelan al riesgo de la enfermedad y sus consecuencias, para suscitar cambios en los comportamientos de la ciudadanía (Losada et al., 2020).

La propagación de este virus, asociada a la interacción social, ha trastocado los hábitos sociales culturalmente preestablecidos tanto en los países latinoamericanos como en España. La vida de los jóvenes -educados en la socialización- se ha visto afectada por este elemento disruptivo que ha provocado un conflicto de valores (Macassi, 2020). Esto ha suscitado comportamientos transgresores, incrementados por la baja percepción de algunos jóvenes sobre el riesgo, convencidos del menor impacto de la enfermedad en su rango de edad. Por ello, las instituciones sanitarias, medios de comunicación, organizaciones juveniles, universitarias, etc., elaboraron y publicaron -en redes sociales como YouTube- historias audiovisuales dirigidas y/o protagonizadas por jóvenes para promover una mayor identificación con la audiencia juvenil, apelando a su responsabilidad.

En este sentido, el presente estudio de carácter exploratorio analiza spots del contexto sociocultural español y latinoamericano -accesibles en YouTube- orientados a concienciar a los jóvenes frente al COVID-19. Se describen las estrategias comunicativas priorizadas, los recursos técnico-narrativos y los aspectos afectivo-emocionales en los que inciden.

\section{Campañas de concienciación juvenil y salud}

Las estrategias comunicativas para concienciar a los jóvenes frente a riesgos de salud de diversa índole, pueden ser de distinto tipo, atendiendo a la revisión teórica realizada: a) informativas, para explicar fenómenos, procesos de trasmisión de enfermedades, causas y consecuencias ligadas a conductas poco saludables, apelando a expertos, simulaciones, demostraciones, etc. (Cuesta et al., 2011; Rodríguez et al., 2018); b) storytelling, recreando historias de fácil identificación donde la trama se relaciona con el fenómeno descrito, buscando empatizar e implicar a la audiencia y subrayando sus rasgos identitarios para movilizarla (Hermann-Acosta, 2020); c) testimoniales, cuyos protagonistas cuentan sus propias vivencias y dotan al relato de mayor nivel de implicación emocional, interpelando a la audiencia con un carácter persuasivo (López-Hermida \& Illanes, 2013); y d) clip-musicales, protagonizados por cantantes de diversos géneros musicales, que aglutinan a audiencias con sensibilidades y gustos distintos, cuyo mensaje se vehicula a través de letras que pueden transitar desde la denuncia social en el rap (Requeijo \& Márquez, 2020) o el hip-hop para prevenir la lacra del acoso escolar (Del Moral et al., 2014).

En general, las campañas publicitarias dirigidas a jóvenes buscan acercarse desde la complicidad y el humor hasta la provocación, e incluso el insulto. Utilizan un lenguaje coloquial, con vocabulario y expresiones propias de su jerga y/o contexto etnográfico (Morales, 2020). Su capacidad persuasiva reside en la conjugación armónica de la creatividad y la empatía, creando mensajes con giros de doble sentido y metáforas que favorecen su vinculación afectivo-emocional (Castello \& Del-Pino, 
2019). Buscan recrear escenarios compartidos donde establecen sus relaciones, facilitando su identificación y proyección con el relato. Igualmente, apelan a sus preferencias de ocio ligadas a las mecánicas y dinámicas de los videojuegos, con intención de concienciar frente a problemas sociales (Paredes, 2018), estableciendo una analogía con el enfoque conductista que explica sus comportamientos y consecuencias, a nivel individual y colectivo. Asimismo, utilizan las redes y medios sociales para generar un flujo de opiniones frente a la temática que les concita (Saavedra et al., 2020), evidenciando su respuesta emocional, mediante hashtag, comentarios, menciones, asignación de likes, etc.

Asimismo, las campañas preventivas de salud de distinto tipo (tabaquismo, embarazos juveniles, etc.) suelen apoyarse en una voz en off que describe la acción e interpela a la audiencia haciéndola partícipe y corresponsable de los hechos narrados. Cobra relevancia el discurso oral, cuyo hilo conductor recae en distintos tipos de protagonistas: a) sanitarios, con un carácter informativo y didáctico (Pérez-Moedano et al., 2021), acompañado de textos, animaciones, infografías, etc. (Burgos-García, 2019); b) afectados, narrando sus propias vivencias (López-Hermida \& Illanes, 2013); c) comunicadores, alertando del riesgo y comprometiendo a la población en una causa común (Martínez, 2020), celebridades (cantantes, futbolistas, etc.) o influencers, aprovechando su poder de captación y cercanía para persuadir y concienciar a sus seguidores (Torres \& Mirón, 2020); o d) promoviendo el efecto espejo, empoderando a una ciudadanía anónima para proyectarse -al formar parte de su propio colectivo-, y empatizar, al establecer relaciones afectivas de índole familiar.

Focalizando el análisis en las campañas de concienciación frente al COVID19, se constata que los spots se consideran recursos narrativos idóneos para contar historias e implicar emocionalmente a la audiencia. Igualmente, las instituciones político-sanitarias internacionales, conscientes del poder mediático de los medios sociales, han optado por el uso estratégico de YouTube como vehículo de difusión masiva de noticias sobre el COVID19 -tal como constatan Gil et al. (2020)-. Esta plataforma les permite llegar a los jóvenes a través de mensajes cortos e impactantes (spots preventivos del coronavirus), para compartir contenidos en otras redes, contribuyendo a su viralización favoreciendo la concienciación y movilización colectiva (Basch et al., 2020a, 2020b). En concreto, en España y Latinoamérica - contextos con rasgos socio-culturales compartidos- han proliferado este tipo de relatos con el fin de sensibilizar especialmente a la población juvenil para frenar los contagios.

\section{Objetivo}

Esta investigación estudia spots españoles y latinoamericanos $(\mathrm{N}=100)$ dirigidos a concienciar a los jóvenes frente al COVID-19, -publicados en el periodo 01/09/2020-10/01/2021 y accesibles en YouTube-, con objeto de: 1) analizar las variables comunicativas, técnico-narrativas y afectivoemocionales que los definen; y 2) determinar la existencia de diferencias entre ambos contextos de procedencia.

\section{Metodología}

\subsection{Método}

Se adopta una metodología mixta: a) cualitativa, centrada en el análisis de contenido de una muestra de 100 spots ligados a campañas de concienciación frente al COVID-19, utilizando un instrumento diseñado ad hoc, que permite recoger datos cualitativos de cada spot, atendiendo a variables comunicativas, técnico-narrativas y afectivo-emocionales. Se validó -tras definir consensuada y apriorísticamente cada indicador- a partir de la revisión y visionado sistemático de los spots por tres 
codificadores expertos en educomunicación (210 minutos cada uno), durante el mes de febrero 2021. La prueba de fiabilidad inter-codificadores Kappa de Cohen arrojó un $\mathrm{k}=.897$ ( $\mathrm{p}<.000)$, obteniendo una alta fiabilidad al ser $\mathrm{k}>.700$. Y, b) cuantitativa, derivada del tratamiento estadístico descriptivo de los datos recabados, y posterior análisis de varianza (ANOVA) para averiguar la existencia de diferencias significativas en función del contexto sociocultural al que pertenecen los spots, siguiendo los criterios de Hair et al. (2014) y López-Roldán y Fachelli (2016) para estudios sociales. El Análisis de la Varianza o ANOVA compara las medias de los datos relativos a las variables que definen los spots de ambos contextos, considerando las diferencias entre las medias estadísticamente significativas entre los dos grupos cuando $\mathrm{p} \leq .050$, por lo que sólo se indicarán en resultados aquellos casos que lo cumplan. Se utilizó el programa SPSS v.24.

\subsection{Muestra}

Se trata de un muestreo no probabilístico, se seleccionaron spots a través del motor de búsqueda de YouTube publicados en el periodo 1/09/2020- 10/01/2021, atendiendo a tres descriptores: temático ("spot coronavirus"), audiencia ("jóvenes") y geográfico (indicando el nombre de cada país latinoamericano, y España), considerando que el orden de aparición viene determinado por el número de visualizaciones y alcance. Los spots fueron seleccionados siguiendo los siguientes criterios: a) dirigidos a la audiencia juvenil; b) orientados a concienciar y prevenir frente al COVID-19. Así, tras eliminar los repetidos, la muestra quedó conformada por un total de 100 spots, 50 españoles y 50 latinoamericanos, que presentaban en su conjunto 4.037.383 visualizaciones en el momento de la consulta (10/01/2021): Argentina (11), Brasil (2), Chile (3), Colombia (3), Costa Rica (3), Cuba (1), Ecuador (2), Honduras (1), México (8), Nicaragua (2), Panamá (1), Perú (6), Puerto Rico (4), El Salvador (1) y Uruguay (2) (ver datos de identificación y visualización en Anexo).

\subsection{Instrumento}

Se creó el instrumento denominado COTECAF -acrónimo de las variables que abarca- sirvió para analizar los spots, identificando las variables comunicativas apuntadas por Yañez y Cusot (2018), técnico-narrativas (Ortiz, 2020) y afectivo-emocionales (González-Oñate et al., 2019; Tomba et al., 2018), junto a las categorías que integran cada una (Tabla 1). 
Tabla 1. COTECAF: Variables COmunicativas, TÉCnico-narrativas y AFectivo-emocionales de los spots anti-COVID 19.

\section{Variables comunicativas}

1.1. Objetivo principal:

- Uso de mascarillas - Hábitos de higiene

- Reuniones/fiestas - Respetar cuarentena
- Distanciamiento social

- Respeto de todas las normas

1.2. Ámbito de incidencia preferente:

- Conceptual (informa o presenta datos) - Procedimental (indica fases de procesos)

- Actitudinal (suscita cambios de conductas)

1.3. Idea fuerza/slogan:

- Cuidado personal - Cuidado de los mayores

- Respeto de normas - Responsabilidad

1.4. Teoría psicológica del aprendizaje:

- Modelizadora positiva - Modelizadora negativa - Constructivista - Conductista

1.5. Carácter predominante del mensaje:

- Educativo - Amenazador - Culpabilizador. - Motivador - Proactivo - Reflexivo - Exhortativo

\section{Variables técnico-narrativas}

2.1. Estrategia narrativa adoptada:

$\begin{array}{lllll}\text { - } & \text { Humor/sarcasmo } & \text { - Provocación/insulto } & \text { - Musical } & \text { - Storytelling/cuento } \\ \text { - } & \text { Demostración } & \text { - Testimonio } & \text { - Informativo } & \text { - Ficción } \\ \text { - } & \text { Simulación (real-animación)/videojuego } & \text { - Documental } & \end{array}$

2.2. Soporte del mensaje:
- Diálogos
- Voz en off
- Animación
- Texto/infografías
- Imágenes
- Música/sonido
- Discurso oral
2.3. Perfil de los protagonistas/hilos conductores del mensaje:
- Sanitarios
- Comunicador (actores/humoristas/influencer)
- Cantante
- Futbolista
- Ciudadanía
- Afectado/a
- Sin protagonistas

- Cuidado general

- Prevención

2.4. Escenario:
- Campo futbol
- Hospital
- Cementerio
- Discoteca - Contexto escolar
- Calle/terrazas - Hogar
- Estudio de grabación
- Paisaje natural

2.5. Tipo de planos predominantes: - PD - PP - PM - PA - PG - GPG
2.6. Colorido:
- Tonal
- Blanco/ negro
- Combinación de ambos
2.7. Iluminación:
- Natural
- Artificial

\section{Variables afectivo-emocionales}

3.1. Interpela a la audiencia para (elección múltiple):

- Favorecer la identificación - Informar - Promover la reflexión - Modificar conductas

- Persuadir - Alertar/atemorizar con la muerte - Incrementar la noción del riesgo

3.2. Emociones/sentimientos positivos que suscita en la audiencia (elección múltiple):
- Esperanza/Empatía
- Solidaridad
- Compasión
- Confianza
- Simpatía - Ninguna/o

3.3. Emociones/sentimientos negativos que genera al espectador/a (elección múltiple):
- Rechazo
- Tristeza
- Rabia/ ira
- Miedo/alerta
- Culpa
- Intranquilidad/ ansiedad - Impotencia - Ninguno/a

3.4. Actitudes negativas encarnadas en personajes (elección múltiple):

- Egoísmo - Indiferencia - Irresponsabilidad/ inconsciencia - Remordimiento - Transgresión - Ninguna

3.5. Actitudes positivas encarnadas en personajes (elección múltiple)

- Responsabilidad - Cooperación - Concienciación - Compromiso - Respeto - Ninguna

Fuente: elaboración propia. 


\section{Resultados}

Tras el análisis de los spots se observa que, respecto al tipo de producción, un 94\% son institucionales, un $4 \%$ producidos por agencias comerciales u ONGs y un $3 \%$ elaborados por jóvenes. Un 55\% están protagonizados por un colectivo mixto, un $18 \%$ por personajes masculinos, un $18 \%$ por femeninos y un $9 \%$ son animaciones textuales. En relación a las edades de los protagonistas, un 8\% son menores de 18 años, un 47\% tienen entre 18-35 años, un 15\% entre 35-65 años, un $3 \%$ son mayores de 65 años, un $18 \%$ incluye grupos intergeneracionales y un $9 \%$ carece de protagonistas al tratarse de animaciones con textos (Tabla 2).

Tabla 2. Distribución porcentual de los spots según la edad del protagonista y contexto sociocultural.

\begin{tabular}{|l|c|c|c|c|c|}
\hline \multicolumn{1}{|c|}{ Edades de protagonistas } & Latinoamérica & España & Total & $X$ & DT \\
\hline Menores de 18 años & -- & 8 & 8 & 8 & -- \\
\hline 18-35 años & 21 & 26 & 47 & 23.5 & 3.54 \\
\hline 35-65 años & 12 & 3 & 15 & 7.5 & 6.36 \\
\hline Más de 65 años & 2 & 1 & 3 & 1.5 & 0.71 \\
\hline Intergeneracional & 9 & 9 & 18 & 9 & 0.00 \\
\hline Animación textual & 6 & 3 & 9 & 4.5 & 2.12 \\
\hline
\end{tabular}

Fuente: elaboración propia.

Se constata que en su conjunto los spots están protagonizados por jóvenes de 18-35 años. Al realizar el contraste de medias -mediante el análisis de la varianza (ANOVA)-, se detectan diferencias significativas en función de contexto, pues los spots latinoamericanos optan por protagonistas de 3565 años ( $\mathrm{p}$ <.000). Asimismo, se evidencian diferencias respecto al objetivo de los spots y la edad de sus protagonistas. Aquellos que priorizan el uso de mascarillas están protagonizados por personas de 18-35 años $(\mathrm{p}<.039)$. Los spots centrados en el distanciamiento social son interpretados por mayores de 65 años ( $<.031$ ), apelando a su vulnerabilidad y necesidad de cuidado. Los que inciden en las reuniones sociales o fiestas están protagonizados por grupos intergeneracionales $(\mathrm{p}<.009), \mathrm{y}$ los que se dirigen al cumplimiento de todas las normas no incluyen protagonistas ( $\mathrm{p}<.001)$, dado su componente textual informativo.

\subsection{Variables comunicativas}

\section{- Objetivo prioritario}

A pesar de que el uso de mascarillas y los hábitos de higiene (lavado de manos y uso de gel hidroalcohólico) son prácticas generalizadas, sigue habiendo spots en este sentido, un $6 \%$ y $4 \%$ respectivamente, que instan a la ciudadanía a su cumplimiento. Un 13\% incide en el mantenimiento de la distancia social, y más concretamente, un $22 \%$ enfatiza la necesidad de evitar reuniones o fiestas multitudinarias ante la proximidad de las fiestas navideñas. Y dado el número de contagios, $\mathrm{y}$ la necesidad de mantenerse aislado para proteger a los demás, un 5\% hace un llamamiento explícito a 
respetar la cuarentena. No obstante, el $50 \%$ de los spots inducen al cumplimiento de todas las normas de prevención (Tabla 3).

Tabla 3. Distribución porcentual de los spots según el objetivo prioritario y contexto sociocultural.

\begin{tabular}{|l|c|c|c|c|c|}
\hline \multicolumn{1}{|c|}{ Objetivo prioritario } & Latinoamérica & España & Total & X & DT \\
\hline Uso de mascarillas & 2 & 4 & 6 & 2 & 1.41 \\
\hline Hábitos de higiene & 3 & 1 & 13 & 6.5 & 6.36 \\
\hline Distanciamiento social & 11 & 2 & 22 & 11 & 2.83 \\
\hline Reuniones/ fiestas & 9 & 13 & 5 & 2.5 & 0.71 \\
\hline Respetar cuarentena & 3 & 2 & 50 & 25 & 4.24 \\
\hline Respeto de todas las normas & 22 & 28 & & & \\
\hline
\end{tabular}

Fuente: elaboración propia.

Posteriormente, el ANOVA evidencia diferencias significativas atendiendo al contexto sociocultural y el objetivo de los spots. Así, los españoles intentan persuadir a la audiencia para evitar reuniones sociales y fiestas multitudinarias, promover el uso de mascarillas $\mathrm{y}$, en general, el cumplimiento de todas las normas sanitarias ( $\mathrm{p}<.044)$. Mientras, los latinoamericanos inciden en el distanciamiento social, los hábitos de higiene y el respeto de la cuarentena $(\mathrm{p}<.009)$. Asimismo, atendiendo a la localización geográfica donde se encuentran los países y el objetivo del spot se observan diferencias significativas. En América del Sur se enfocan a evitar las reuniones o fiestas y al respeto de la cuarentena ( $\mathrm{p}$.014), en América Central promueven los hábitos de higiene y el uso de mascarillas $(\mathrm{p}<.000)$, y en países latinoamericanos ubicados en el norte de América inciden en el distanciamiento social $(\mathrm{p}<.001)$.

\section{- Ámbito de incidencia preferente}

Un $55 \%$ de los spots posee un carácter actitudinal, busca suscitar cambios de conducta en la audiencia, apelando a la reflexión sobre las consecuencias de los actos irresponsables e implicándola emocionalmente. Un $42 \%$ trata aspectos procedimentales relacionados con el lavado de manos, el modo adecuado de ponerse la mascarilla, el mantenimiento de $1.5 \mathrm{~m}$ de distancia social, ventilación de espacios, etc. Y un 3\% aborda temas de índole conceptual sobre el virus y su forma de contagio, aportando información sobre la evolución de la pandemia, sin matices emocionales (Tabla 4).

Tabla 4. Distribución porcentual de los spots según el ámbito de incidencia y contexto sociocultural.

\begin{tabular}{|l|c|c|c|c|c|}
\hline Ámbito de incidencia & Latinoamérica & España & Total & X & DT \\
\hline Conceptual & 2 & 1 & 3 & 1,5 & 0.71 \\
\hline Procedimental & 27 & 15 & 42 & 21 & 8.49 \\
\hline Actitudinal & 21 & 34 & 55 & 27,5 & 9.19 \\
\hline
\end{tabular}

Fuente: elaboración propia. 
El posterior ANOVA contrastando el ámbito de incidencia y el contexto sociocultural, evidencia que los spots españoles priorizan relatos de carácter actitudinal $(\mathrm{p}<.004)$, y los latinoamericanos los de índole procedimental, orientados a promover prácticas saludables $(\mathrm{p}<.010)$. Además, al considerar la edad y el ámbito, se observa que los spots de tipo procedimental están protagonizados por personas de 18-35 años ( $\mathrm{p}<.006)$, mientras los actitudinales lo están por sujetos de 35-65 años ( $\mathrm{p}<$ $.000)$.

\section{- $\quad$ Slogan/Idea fuerza}

El 30\% de los eslóganes: "cuídate tú y cuida de todos", "cuida de tus mayores", "practiquemos la cuidadanía", "por tí y por los demás", "cuidate vos, cuida de ellos", "cuidémonos entre todos", "el mejor regalo es cuidarnos", "seguí cuidándote", etc., remiten al valor del cuidado de la ciudadanía. En concreto, un $9 \%$ al cuidado personal, un $6 \%$ específicamente dirigido al cuidado de los mayores, y otro $15 \%$ al cuidado en general, dentro del contexto de riesgo ligado a las fiestas navideñas. El $26 \%$ de los eslóganes inciden en el respeto de normas: "evitemos las reuniones" (spot 51), "game over" (spot 34), "quédate en casa, cierra la puerta a los contagios" (spot 18), "no te pilles un rebrote"(spot 9), "la última copa" (spot 16), "esto no es un juego" (spot 22), etc. Un 24\% alude a la responsabilidad personal: "tu responsabilidad salva vidas" (spot 10), “ilo pillas?" (spot 32), "si la lías, nos la lías a todos" (spot 42), "el COVID no mata solo, no seas cómplice" (spot 88), "lo que el COVID se llevó" (spot 8). Y un 20\% exhorta a la prevención: "evita los rebrotes" (spot 4), "en Navidad, tú decides con quién te sientas" (spot 28), "ser joven no te protege" (spot 35), "Navidad sin COVID” (spot 76), "no bajemos la guardia" (spot 89), etc.

Al contrastar las medias -mediante el ANOVA- el tipo de eslóganes adoptados en los spots atendiendo al contexto sociocultural, no se encontraron diferencias, todos convergen en la misma idea de cuidado, responsabilidad y prevención.

\section{- Teoría psicológica del aprendizaje que subyace}

La teoría modelizadora de Bandura (1990) subraya que el aprendizaje humano se sustenta en la imitación de modelos, donde el refuerzo es vicario. En los spots analizados, se observa que el $60 \%$ utiliza modelos, y de ellos, un $44 \%$ invita a la audiencia a adoptar comportamientos saludables, exhibiendo conductas positivas, mientras el restante $16 \%$ propone contramodelos, muestra conductas reprobables con final trágico, buscando disuadir. Otro $25 \%$ se adscribe a postulados constructivistas (Bruner, 1988), proporcionan un aluvión de estímulos visuales y sonoros impactantes (cementerio, ataúd, latidos de corazones agonizantes, respiraciones entrecortadas, etc.), buscando la complicidad del espectador para elaborar el relato a partir de sus experiencias, conocimientos previos y asociación de ideas.

Por otra parte, un $15 \%$ de los spots adoptan fórmulas conductistas, de corte skinneriano, incidiendo en los refuerzos negativos -o castigos- ligados a conductas irresponsables o egoístas, tornándose en negro los relatos y mostrando la cruda realidad de la enfermedad: personas entubadas en hospitales o muerte. Y, suelen utilizar expresiones y juegos de palabras como: deshojar margaritas: "lo pillo, no lo pillo, lo pillo, ...: "esta vez está en tus manos" (spot 33); o, apelando al riesgo de tomarlo como un juego con connotaciones negativas: "esto no es un juego" (spot 22), "Game Over" (spot 34), o desde el azar: "pito, pito, gorgorito, pim, pam: tú” (spot 47).

Tampoco se encontraron diferencias respecto a la teoría psicológica que respalda a los spots en función del contexto sociocultural, pues parten de postulados semejantes. 


\section{Carácter predominante del mensaje}

Los estados han enfatizado determinados mensajes en sus spots institucionales en un intento de persuadir a la ciudadanía. Así, un $23 \%$ posee un tono proactivo, invitando a adoptar medidas concretas relacionadas con el cumplimiento de normas. Un $20 \%$ incide en mensajes educativos, enunciando medidas sanitarias y mostrando pautas de actuación. Otro $20 \%$ adopta un tono culpabilizador, presentando situaciones que evidencian las consecuencias de la falta de responsabilidad de los jóvenes, por ejemplo, utilizando una metáfora que identifica el no guardar la cuarentena con salir a la calle con una pistola cargada (spot 10). Un $11 \%$ induce a la reflexión ante hechos no deseables que pueden evitarse cambiando de actitud. Un 10\% se muestran amenazadores, subrayando imágenes de enfermos en hospitales y cementerios e incorporando sonidos recurrentes (latidos, ritmos, grados, respirador, etc.) que envuelven en una atmósfera de intranquilidad al relato. Un 8\% refleja un carácter motivador, apostando por mensajes positivos impregnados de esperanza. $\mathrm{Y}$, otro $8 \%$ denota la preocupación por las víctimas, exhortando a velar por la salud de todos.

El análisis de varianza entre las variables carácter predominante del mensaje y el contexto sociocultural no arrojó diferencias significativas, dado que los spots de ambos contextos abarcan una gran variedad de enfoques, y no destacan especialmente por su carácter predominante.

\subsection{Variables técnico-narrativas}

Las variables técnico-narrativas que definen los spots estudiados abarcan la identificación de la estrategia narrativa adoptada, el soporte del mensaje preferente, los protagonistas o hilos conductores seleccionados, los escenarios escogidos, la prevalencia de un determinado tipo de plano y el colorido e iluminación elegidos.

\section{- Estrategia narrativa}

El 32\% de los spots opta por el storytelling, de los cuales la mitad (16\%) son relatos protagonizados por jóvenes que se hallan en lugares de ocio con amigos, en ocasiones transgrediendo las normas sanitarias, mostrándoles como asintomáticos irresponsables y culpabilizándoles de los contagios. Y, la otra mitad de estos spots recrean escenas cotidianas, donde los jóvenes interaccionan a través de tabletas, móviles, usando WhatsApp, etc., subrayando su compromiso con la salud de los más vulnerables y movilizando a más comunidades. Por otro lado, un $16 \%$ utiliza el testimonio como recurso narrativo, presentando a afectados, influencers, sanitarios, etc., para alertar a los jóvenes sobre la crudeza de la enfermedad. Un 14\% apela a la simulación, intercalando elementos reales y ficticios, e incluso, algunos utilizan las mecánicas de avance y retroceso de los videojuegos (con el joystick), y su lenguaje (game over) para conectar con la juventud. Un 13\% posee un tono de demostración, ligado a explicar procedimientos para cumplir las normas sanitarias (colocarse la mascarilla, distanciamiento social...), así como censurar conductas reprobables.

En menor medida, un $12 \%$ participa del género informativo, en su mayoría animaciones, esquemas y textos divulgativos con fines didácticos: qué es el virus, cómo se transmite y cómo se pueden evitar los contagios. Un 5\% adopta el formato de videoclip musical, protagonizado por cantantes y/o raperos populares entre los jóvenes, asegurando la recepción del mensaje. Un $4 \%$ recurre al humor o al sarcasmo para reducir el efecto dramático de la pandemia, caricaturizando situaciones cotidianas ligadas al respeto de normas, representadas por humoristas conocidos que promueven actitudes responsables. Un 3\% se adhiere al género documental, exponiendo datos para dotar de rigor científico a la información vertida. Y un marginal 1\% recurre a la provocación y al insulto ("no seas 
imbécil" (spot 46), con interpelaciones directas y agresivas en segunda persona y en modo imperativo.

Tampoco se encontraron diferencias estadísticas significativas tras efectuar el ANOVA entre las variables estrategia narrativa adoptada en los spots y su contexto de referencia, dado que hay una gran variedad, no se prima una en especial para este tipo de comunicación ligada a la salud.

\section{- $\quad$ Soporte del mensaje}

En el $85 \%$ de los spots las imágenes son el principal soporte del mensaje, acompañadas en su mayoría de distintos elementos sonoros para enfatizarlo, conscientes de que una imagen vale más que mil palabras (gráfico 1). Un 58\% incorpora infografías o textos con carácter explicativo, relativos a las normas o datos de evolución de la pandemia (infectados y fallecidos). Un $41 \%$ utiliza la música o la ambientación sonora, estableciendo contrastes entre: músicas festivas y fúnebres, canciones en discoteca y el sonido de una UCI, o apelando al significado cultural del toque de campana de una iglesia que recuerda a los difuntos (spot 23); otros utilizan las letras de canciones para interpelar a los jóvenes en un tono desafiante (spot 42$)$.

Un 38\% se decanta por usar la voz en off para promover la reflexión, casi siempre, para verbalizar los pensamientos del protagonista teñidos por el remordimiento. Un 34\% se sirve de personajes para pronunciar un discurso oral directo, con carácter exhortativo y proactivo, apelando a la responsabilidad y al compromiso de los jóvenes. Las animaciones representan un 19\%, utilizan personajes de cómic o ilustraciones con valor didáctico y lúdico para ejemplificar el cumplimiento de normas, abriendo el abanico a otras audiencias de menor edad. Y, un 14\% se apoya en diálogos entre personajes, a menudo, jóvenes que comentan con sus amigos la inconveniencia de organizar fiestas para evitar los contagios en su ámbito familiar, aportando argumentos para disuadir o concienciar al respecto (Gráfico 1).

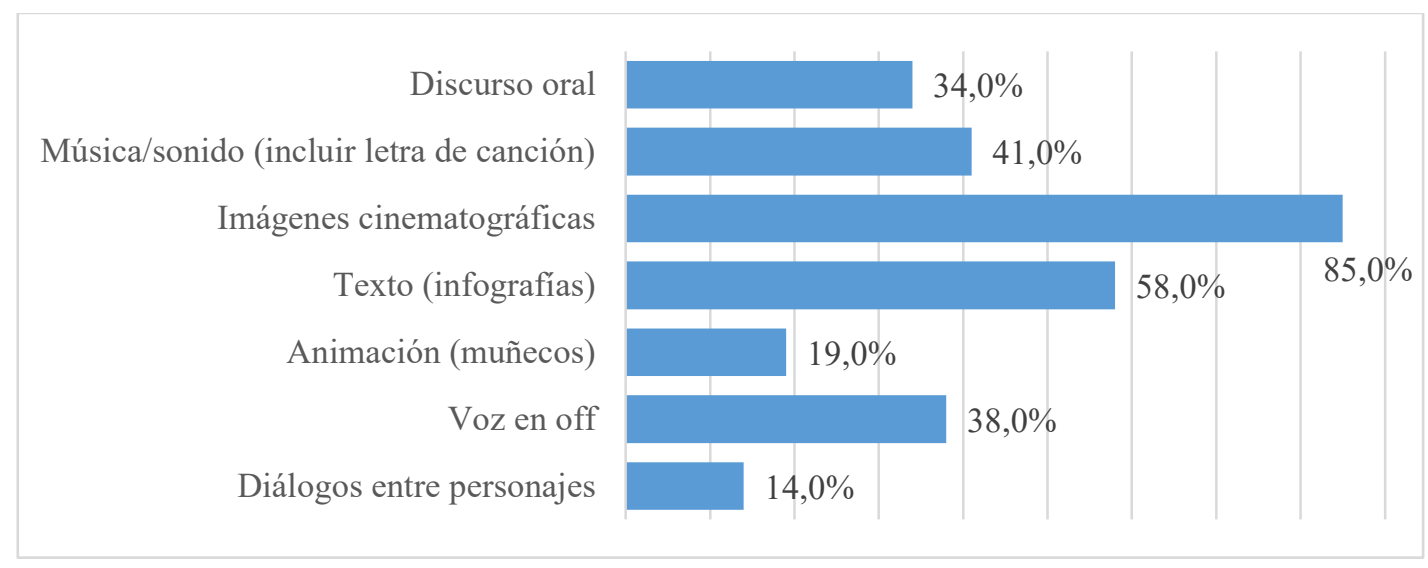

Gráfico 1. Soporte preferente utilizado para transmitir el mensaje.

Fuente: elaboración propia.

Tampoco se encontraron diferencias significativas respecto a la prioridad concedida al soporte del mensaje en los spots atendiendo al contexto sociocultural, ambos coinciden en la utilización de soportes semejantes.

\section{- Protagonistas/ hilos conductores}


El 57\% de los protagonistas de los spots corresponde a una ciudadanía anónima, para facilitar la proyección de la audiencia con sus iguales, casi siempre representada por miembros de la unidad familiar, enfatizando el lazo del parentesco (hijo/madre, nietos/abuelos, abuela viuda, etc.) apelando a la responsabilidad del cuidado de los mayores y subrayando el compromiso de los jóvenes con causas sociales (24\%). Sin embargo, un 33\% responsabiliza a los jóvenes de la enfermedad y muerte de familiares o amigos por transgredir las normas. También se observa la especial victimización del género femenino (abuelas o madres contagiadas y fallecidas), y la incriminación del género masculino como cómplices de los contagios. No obstante, la figura de la superwoman encarnada en Susana Distancia (spot 83: México) empodera a las mujeres como protectoras.

Por otro lado, un 14\% de los spots están protagonizados por comunicadores o personajes conocidos, (actores o cantantes) (3\%), humoristas, futbolista: Maradona (2\%) (spots 53-61) e influencers, dado su gran impacto en las audiencias. Tan solo un $8 \%$ está protagonizado por sanitarios, por entender que pueden ofrecer una mayor credibilidad dada su proximidad a la realidad de la enfermedad. De forma similar, un $7 \%$ presenta a afectados que cuentan emocionados sus padecimientos en primera persona. Un $9 \%$ no posee protagonistas, dado el soporte animado y carácter informativo (tabla 5).

Tabla 5. Distribución porcentual de los spots según el perfil del protagonista y contexto sociocultural.

\begin{tabular}{|l|c|c|c|c|c|}
\hline \multicolumn{1}{|c|}{ Protagonista } & Latinoamérica & España & Total & X & DT \\
\hline Ciudadanía anónima & 27 & 30 & 57 & 28,5 & 2.12 \\
\hline $\begin{array}{l}\text { Comunicadores o personajes } \\
\text { conocidos }\end{array}$ & 12 & 2 & 14 & 7 & 7.07 \\
\hline Sanitarios & 3 & 5 & 8 & 4 & 1.41 \\
\hline Afectados & 0 & 7 & 7 & 3,5 & 4.95 \\
\hline Cantantes & 0 & 3 & 3 & 1,5 & 2.12 \\
\hline Futbolista & 2 & 0 & 2 & 1 & 1.41 \\
\hline Sin protagonistas & 6 & 3 & 9 & 4,5 & 2.12 \\
\hline
\end{tabular}

Fuente: elaboración propia.

Tras el ANOVA, se constata que los spots españoles destacan significativamente por estar protagonizados por una ciudadanía anónima, afectados, cantantes y sanitarios ( $<<.000)$, mientras en los spots latinoamericanos, los protagonistas son comunicadores o personajes conocidos (futbolistas preferentemente) $(\mathrm{p}<$.033). También se evidencian diferencias atendiendo a la edad de los protagonistas. Los spots protagonizados por una ciudadanía anónima incluyen personas de 18-35 años o grupos intergeneracionales $(\mathrm{p}<.013)$, como era de esperar.

\section{- Escenarios}

Un 24\% de los spots desarrollan su trama en calles o terrazas, lugares de socialización de los jóvenes y un $1 \%$ en discotecas y ambiente festivo. Un 18\% remite al hogar, donde tienen lugar encuentros familiares intergeneracionales, incidiendo en el riesgo que implica el no guardar las normas sanitarias. Otro $18 \%$ se ha elaborado en estudios de grabación para transmitir mensajes directos, la mayoría protagonizados por comunicadores. Un $17 \%$ utiliza el hospital como escenario para subrayar la peligrosidad de la enfermedad, recreando una ambientación asfixiante, y un 1\% sitúa al 
espectador en un cementerio (fig. 1 y 2). Desde una perspectiva más positiva, un $7 \%$ utiliza paisajes naturales para invitar a respetar las normas. Solo un 3\% se sitúa en contextos escolares para recalcar las normas de higiene y distancia. Un $2 \%$ se enmarca en un campo de fútbol, donde Maradona representa la promesa de victoria contra el virus, aludiendo a las jornadas de gloria de la selección argentina. Y, el 9\% de las animaciones o paneles informativos no tiene un escenario concreto.
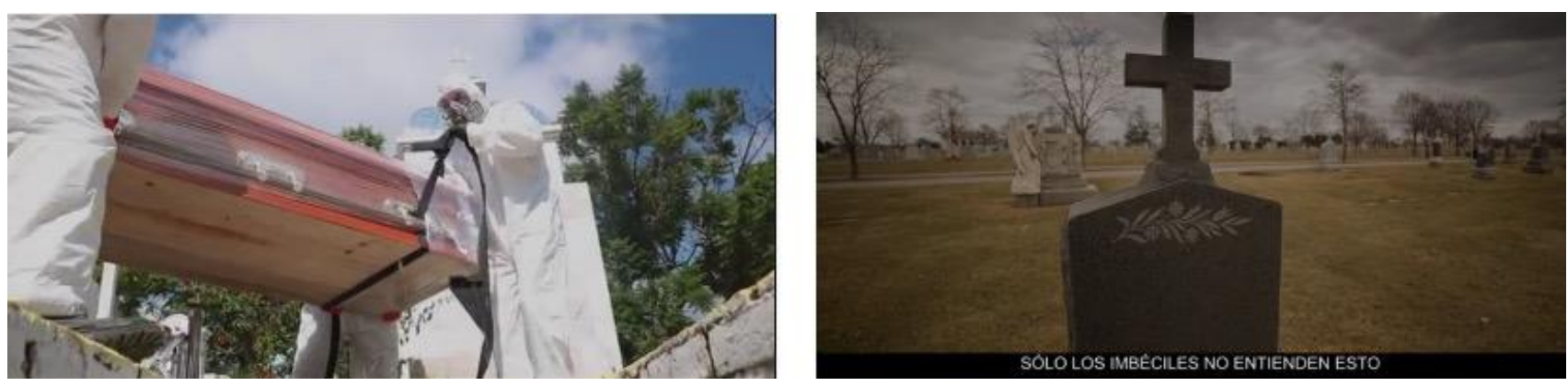

Fig. 1 y 2. El cementerio como destino final tras las fiestas sin protección.

Fuente: Spots (079) y (046) en YouTube (ver anexo).

\section{- Tipos de plano predominante}

Un $60 \%$ de los spots utiliza planos medios o primeros planos, para focalizar la atención de la audiencia. Concretamente, el 38\% que opta por el plano medio enfocar al interlocutor, mostrando su postura e ilustrando modos de lavarse las manos, ponerse las mascarillas, etc., y el $22 \%$ prioriza los primeros planos de personajes (comunicadores, afectados, cantantes, etc.) que interpelan directamente al espectador: "Ya sabes lo que tienes que hacer" (spot 14), "No seas imbécil" (spot 46), "Por mí, no te vas a contagiar" (spot 37), etc., buscando empatizar con el espectador y promover su reflexión. Por su parte, el $23 \%$ que prima el plano general, ubica a los protagonistas en escenarios exteriores y suele relacionar el mensaje con la distancia social. De forma marginal, solo un $4 \%$ usa el plano americano en situaciones cotidianas en el hogar y en igual proporción, otro $4 \%$ apuesta por el plano detalle para mostrar rostros de personas entubadas en camas de hospital, subrayando el dolor y la impotencia frente a la enfermedad (Fig. 3 y 4). El 9\% de los spots son paneles informativos o animaciones, no destacan planos.
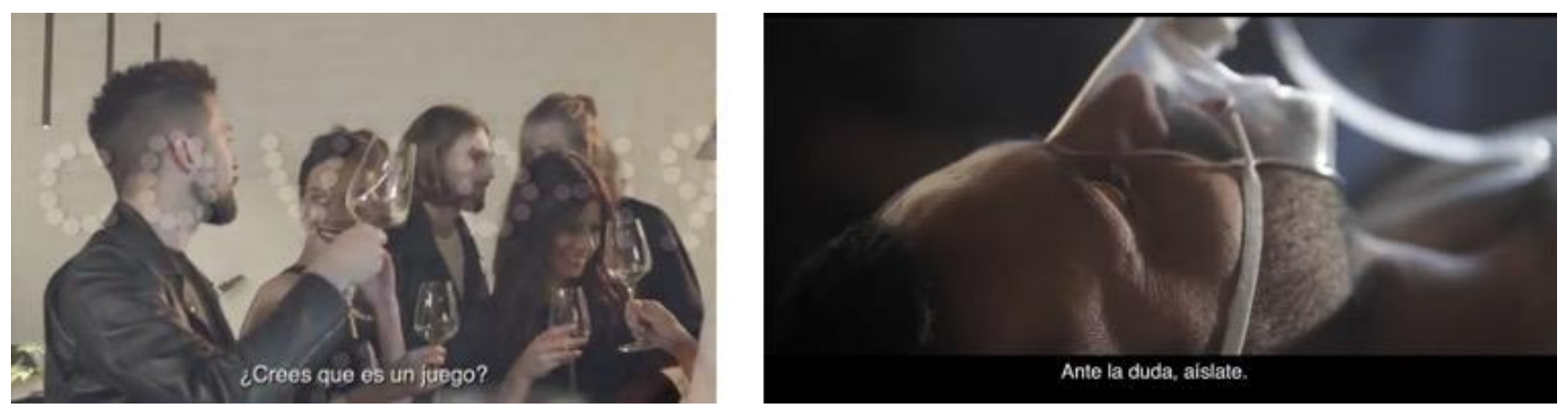

Fig. 3 y 4. Fiestas sin protección y consecuencias.

Fuente: Spots (006) y (010) en YouTube (ver anexo).

\section{- Colorido e iluminación}

Se observa que el $82 \%$ de los spots prima el colorido natural, un $11 \%$ combina el blanco y negro con el color para contraponer el drama (hospital) a la fiesta (discoteca), o bien para dirigir la atención al 
elemento cromático con fines didácticos, al ejemplificar las vías de contagio del virus, o identificar a la persona infectada en un contexto social (Fig. 5 y 6). Tan solo un $7 \%$ utiliza el blanco y negro para incrementar el dramatismo del relato, especialmente en spots de Argentina y México. Respecto a la iluminación, un $62 \%$ opta por luz artificial, mientras el $38 \%$ restante utiliza luz natural, al estar grabados en exteriores.
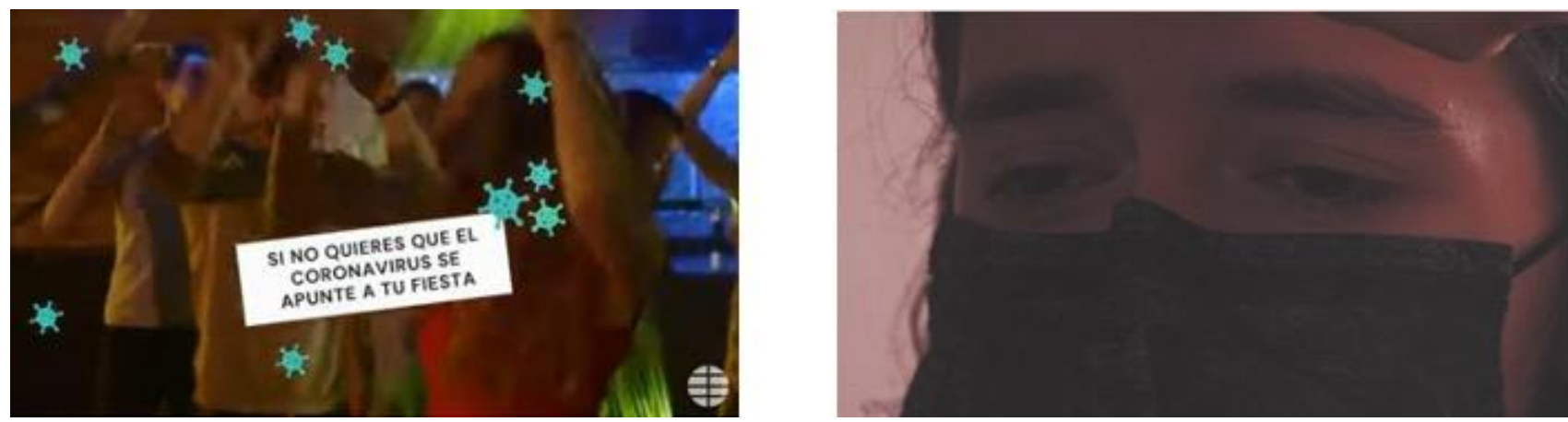

Fig. 5 y 6. Fiestas sin protección y consecuencias.

Fuente: Spots (044) y (002) en YouTube (ver anexo).

Hay que señalar que las variables escenario, tipo de plano predominante y colorido e iluminación de los spots no ofrecen diferencias respecto al contexto sociocultural latinoamericano o español, utilizan recursos semejantes.

\subsection{Variables afectivo-emocionales}

\section{- Finalidad de la interpelación a la audiencia}

El 74\% busca modificar conductas y hábitos en la ciudadanía en relación a las normas sanitarias. Un $69 \%$ interpela, especialmente a los jóvenes, para incrementar la noción de riesgo de la enfermedad. Un $49 \%$ favorece la identificación con el relato de los protagonistas apelando al efecto espejo. Un $33 \%$ promueve la reflexión, mostrando situaciones críticas. Un $31 \%$ atemoriza con la muerte de familiares y personas queridas, en España se hace de forma implícita (sonidos de respirador, caída del ritmo cardiaco, etc.), mientras en Latinoamérica es más explícita mostrando un ataúd. Un 30\% se enfoca a persuadirlos del cumplimiento de las normas higiénicas (mascarilla, gel hidroalcohólico, etc.). Y un $23 \%$ tiene como finalidad informar sobre el virus y sus formas de contagio (Gráfico 2).

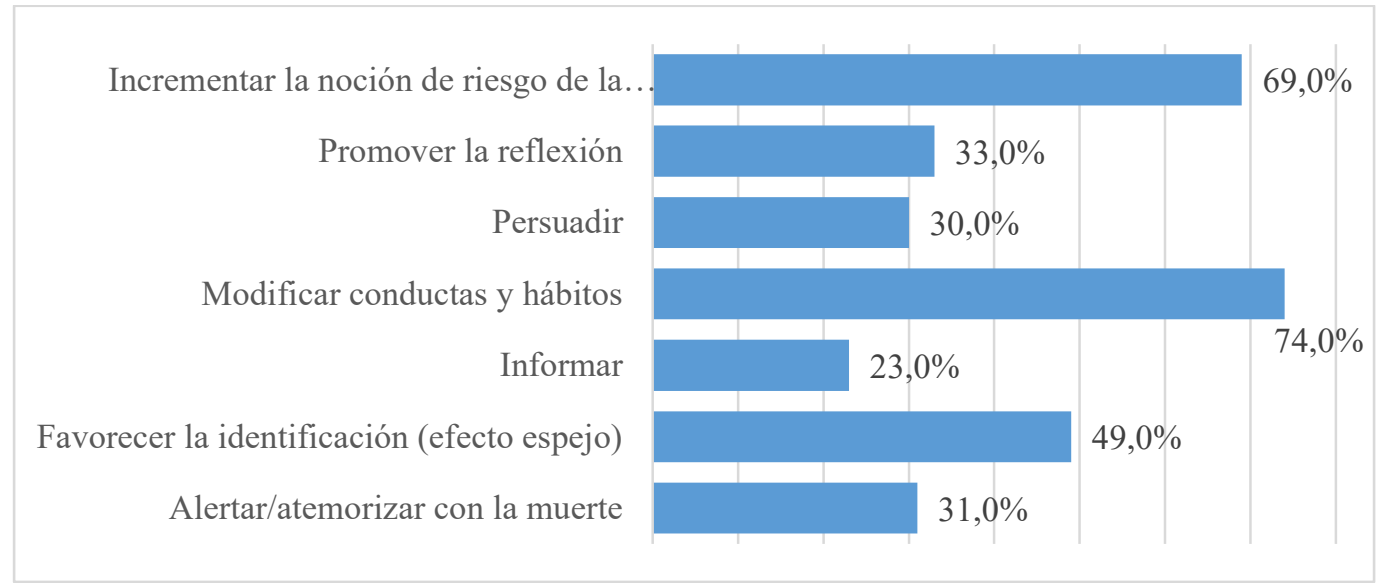

Gráfico 2. Finalidad de la interpelación a la audiencia. 
Fuente: elaboración propia.

\section{- Emociones/ sentimientos positivos que suscitan los spots en la audiencia}

El $44 \%$ apela a la solidaridad de la audiencia y al compromiso con el cuidado de sus conciudadanos, en varios spots se exalta el patriotismo ("El Perú primero" (spots 89-90), "Recorrer nuestro país" (spot 74), "Vivir como galegos" (spot 30), etc. Un 23\% suscita confianza en los espectadores, generalmente ligada a perfiles sanitarios que protagonizan los spots y a comunicadores o personas conocidas que merecen un reconocimiento social. Un 17\% promueve la empatía con el relato y los protagonistas. Un $13 \%$ provoca simpatía en función del tono humorístico del spot, el mensaje optimista de la letra de una canción, etc. Un $12 \%$ provoca compasión ligada a relatos dramáticos de personas que sufren en hospitales. Un $8 \%$ suscita esperanza al comprobar juventud comprometida y responsable que cumple las normas para evitar contagios. Hay que resaltar que un $29 \%$ de los spots no transmiten emociones o sentimientos positivos. Tampoco se encontraron diferencias atendiendo al contexto español o latinoamericano de referencia, pues los spots recurren a emociones compartidas (Gráfico 3).

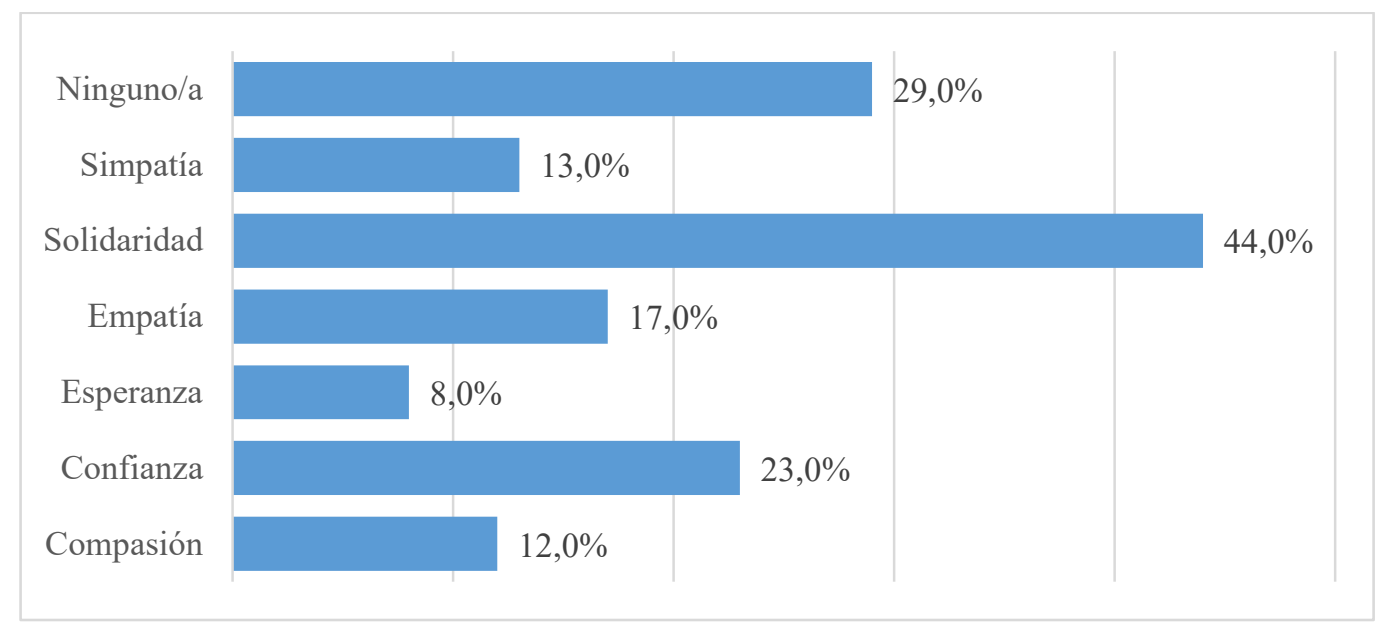

Gráfico 3. Emociones/sentimientos positivos que suscitan los spots en la audiencia.

Fuente: elaboración propia.

\section{- Emociones/ sentimientos negativos que generan los spots en la audiencia}

Un 35\% de los spots generan ansiedad o intranquilidad al mostrar la repercusión del incumplimiento de normas, tales como la participación de jóvenes en fiestas, sin mascarilla y sin guardar la distancia social, etc. De forma similar, un 33\% suscita miedo o alerta en la audiencia al constatar la evolución de la pandemia, así como aquellos que recrean acústica y visualmente las UCI, cementerio, crematorio, etc. Un $20 \%$ provoca tristeza al mostrar a los abuelos en situación de vulnerabilidad y soledad. Un $16 \%$ evoca un sentimiento de culpabilidad en la audiencia juvenil por sus actos irresponsables. Un $14 \%$ provoca impotencia al contemplar situaciones donde se transgreden las normas poniendo en riesgo la salud de los demás. Un 12\% genera rabia o ira cuando la consecuencia de esos comportamientos transgresores y egoístas abocan a la muerte a familiares cercanos. Un 5\% genera rechazo frente a relatos protagonizados por jóvenes que no se hacen cargo de la gravedad de la situación. Y finalmente, un 37\% no genera sentimientos negativos en la audiencia (Gráfico 4). 
RLCS, Revista Latina de Comunicación Social, 79, 23-49

[Investigación] DOI: 10.4185/RLCS-2021-1510| ISSN 1138-5820| Año 2021

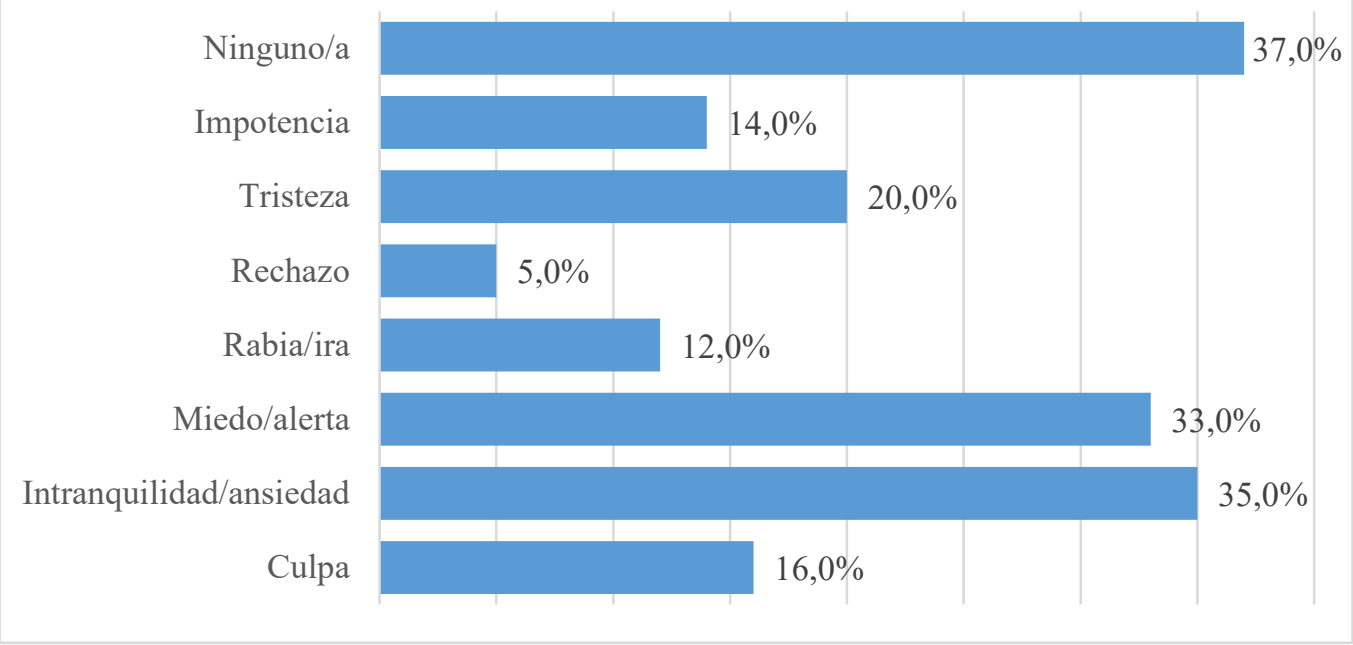

Gráfico 4. Emociones/sentimientos negativos que generan los spots en la audiencia.

Fuente: elaboración propia.

\section{- Actitudes negativas encarnadas en los personajes}

Un $62 \%$ de los personajes que protagonizan los spots no manifiestan actitudes negativas censurables. Un $33 \%$ se muestra con actitudes irresponsables o inconscientes, por no llevar mascarilla, no guardar distancia de seguridad, compartir objetos que pueden ser vehículos de contagio. Un $17 \%$ se manifiesta con actitud egoísta, preocupados solo de su disfrute y beneficio. Un 14\% adopta conductas transgresoras asistiendo a fiestas multitudinarias, botellones, etc., con grave riesgo para ellos y su entorno. Y, un $1 \%$ muestra jóvenes indiferentes, ajenos a las consecuencias de sus actos (Gráfico 5).

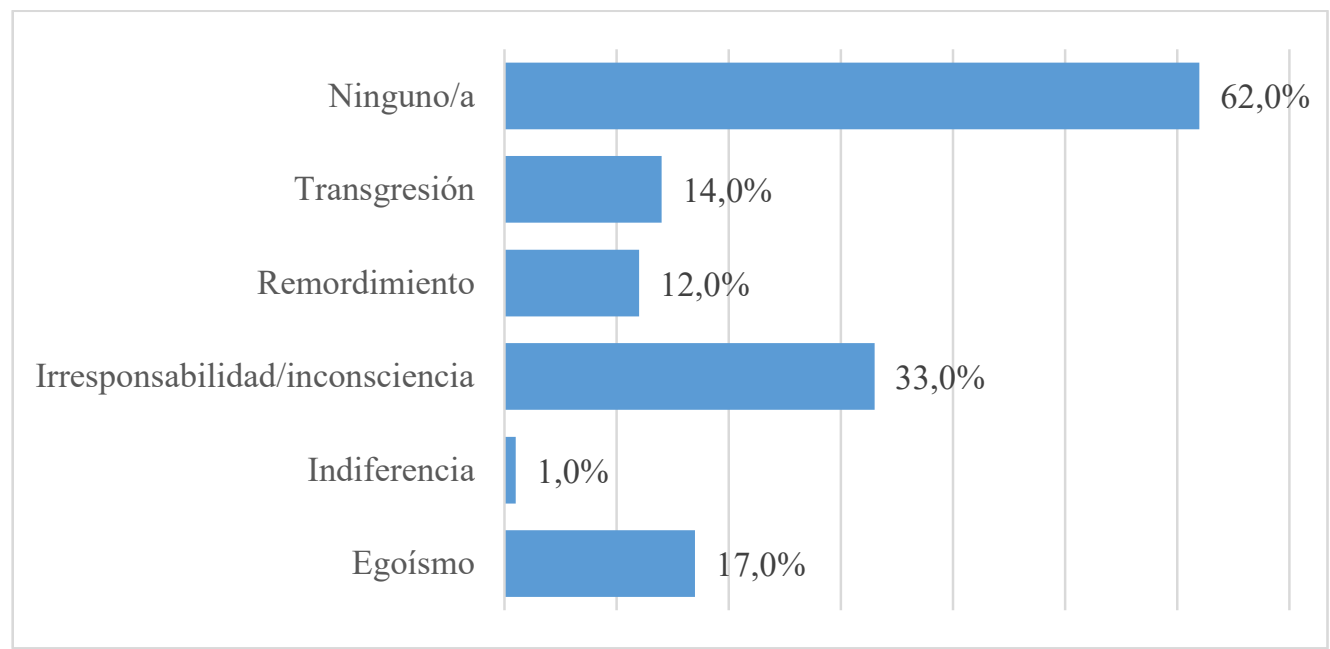

Gráfico 5. Actitudes negativas encarnadas en los personajes.

Fuente: elaboración propia.

\section{- Actitudes positivas encarnadas en los personajes}

El $62 \%$ de los jóvenes protagonistas de los spots se muestran concienciados con la necesidad de cumplir con las normas sanitarias establecidas. Un 45\% reflejan una actitud responsable, portan mascarillas en lugares concurridos, se lavan las manos y usan gel hidroalcohólico. Un 38\% retratan 
jóvenes comprometidos con el fin de la pandemia, invitando a otros a seguir sus pasos, especialmente, limitando sus contactos sociales. Un $22 \%$ se sienten llamados a cooperar de forma activa en la solución del problema sanitario, protagonizando ellos mismos las campañas e interpelando a sus iguales. Otro $22 \%$ muestra jóvenes respetuosos con las normas para evitar el contagio de sus familiares. Un $29 \%$ de los spots no exhiben personajes con actitudes positivas.

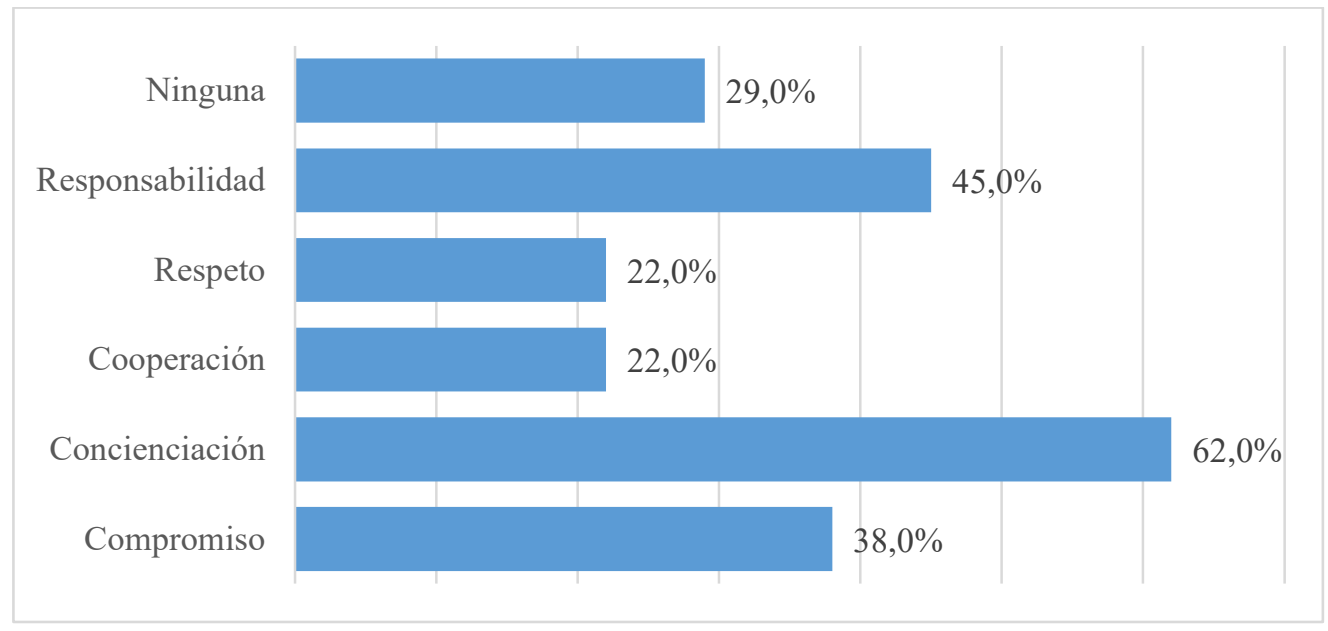

Gráfico 6. Actitudes positivas encarnadas en los personajes.

Fuente: elaboración propia.

En todas las variables afectivo-emocionales que definen los spots analizados no se han encontrado diferencias estadísticamente significativas en función del contexto de referencia, pues se percibe una convergencia en las representaciones que aluden a imaginarios emocionales compartidos.

\section{Discusión y conclusiones}

Como en situaciones semejantes, tradicionalmente las instituciones sanitarias de España y Latinoamérica han subrayado la función educativa de determinadas campañas de salud (Orozco, 2010). En este caso, frente al COVID-19, han difundido spots estratégicamente en YouTube, conscientes de su poder de captación juvenil. Generalmente, los relatos dirigidos a los jóvenes no permanecen ajenos a sus intereses y gustos, uso de las redes sociales como medio de comunicación e interacción (mensajes de WhatsApp, videollamadas, hashtag, etc.), así como la recurrencia a los videojuegos resaltando su estética como fórmula narrativa (Muñoz \& Segovia, 2019).

Los elementos compartidos entre España y Latinoamérica reflejados en los spots analizados -más allá de la lengua- facilitan la comprensión del significado al apelar a rasgos culturales comunes como la familia como eje de la historia, el papel relevante de los abuelos, los encuentros y celebraciones con familiares y amigos; el ocio y la socialización (fiestas, baile y consumo de alcohol); y, el sentimiento patrio vinculado al país o región de origen. Además, todas las historias y vivencias están impregnadas de emociones y sentimientos que involucran al espectador en el plano afectivoemocional. A menudo, se recurre a relatos realistas donde un personaje cuenta su experiencia en primera persona sobre una situación dolorosa, lo que favorece la empatía e incrementa la solidaridad con colectivos vulnerables.

En concreto, los spots analizados, a pesar de contemplar elementos propios del contexto sociocultural de procedencia -que responden a sus condicionantes y peculiaridades-, son pocas las diferencias observadas. 
El objetivo de los spots posee un componente diferencial en función del contexto sociocultural, así los españoles se enfocan en persuadir a la audiencia para: cumplir todas las normas sanitarias, evitar reuniones sociales o fiestas multitudinarias y usar mascarillas, por entender que la relajación de las medidas y la proximidad de las fiestas navideñas podrían incrementar los contagios. Por otro lado, los spots latinoamericanos inciden especialmente en el distanciamiento social, hábitos de higiene y respeto de la cuarentena, dado el incremento de contagios en esas fechas. Además, se observan matices diferenciales relativos a la ubicación geográfica de los países: en América del Sur se preocupan por evitar las reuniones sociales o fiestas y por respetar la cuarentena; en América Central promueven los hábitos de higiene y el uso de mascarillas; y en los países latinoamericanos ubicados en el norte de América se focalizan a concienciar sobre la necesidad del distanciamiento social.

De forma semejante, con relación al ámbito de incidencia, se observa que los spots españoles priorizan relatos de carácter actitudinal, buscando cambios de conductas en los jóvenes; y los latinoamericanos apuestan por fórmulas de índole procedimental, dan pautas sobre hábitos de higiene preventivos. Asimismo, se percibe que los spots españoles son bastante heterogéneos respecto a los perfiles de sus protagonistas, pues optan por una gama amplia: ciudadanía anónima, afectados, cantantes y sanitarios. Mientras que los latinoamericanos apuestan por el impacto del prestigio de comunicadores, personajes conocidos y futbolistas, convencidos de su capacidad persuasiva. Igualmente, se constata que los spots españoles optan en mayor medida por protagonistas de edades entre 18-35 años, en un intento de que los jóvenes se identifiquen con el mensaje que transmiten, provocando el efecto espejo. A diferencia de los latinoamericanos, que incluyen personas de 35-65 años, generalmente para sensibilizar a la audiencia juvenil frente a los riesgos de los mayores, apelando a su solidaridad y responsabilidad.

En ambos contextos se observa una tendencia a representar a la juventud en torno a dos grupos polarizados. Por un lado, muestran jóvenes como modelos ejemplares de conducta, responsables de sus actos, concienciados con la problemática y respetuosos con las normas, e incluso, presentándoles como agentes movilizadores, comprometidos con el bienestar y la salud de todos, al invitar a sus iguales a la cooperación. Y, en el polo opuesto, se observan representaciones ligadas a conductas reprobables, retratándoles como irresponsables por su baja percepción de riesgo, pues aunque comprenden las normas no siempre las aceptan ni cumplen, coincidiendo con lo que señalan Torralbas et al. (2020) en su investigación referida al contexto cubano.

También se constata gran homogeneidad en los componentes afectivo-emocionales de estos relatos. Se percibe una tendencia a incrementar el sentimiento de culpa y a atemorizar con la muerte propia o de familiares, mostrando por un lado, conductas transgresoras individuales (saltándose el toque de queda, no usar mascarilla en espacios compartidos...); y por otro, transgresiones colectivas (participar en fiestas clandestinas multitudinarias). Esto mismo critica Arévalo (2021) aludiendo a la cobertura de noticias sobre el COVID19 protagonizadas por jóvenes. En el contexto peruano, Macassi (2020) considera estos comportamientos como hábitos culturales adquiridos en escenarios sociales compartidos, apoyados en discursos que invitan a la transgresión juvenil como arquetipo. En este sentido, se requeriría una nueva línea de investigación orientada a constatar las opiniones de la audiencia juvenil respecto a las estrategias narrativas utilizadas, su grado de identificación y empatía con los discursos adoptados, así como el nivel de concienciación que imprimen este tipo de spots. De esta forma, se podrían construir nuevos spots que permitan una representación de la juventud alejada de estereotipos estigmatizantes, con carácter proactivo que les invite a adoptar conductas saludables y responsables.

Finalmente, hay que reseñar que si bien la muestra es amplia, teniendo presente los criterios de selección, existe una descompensación en la representación de los spots de algunos países 
latinoamericanos. Quizás, la diferente asignación presupuestaria de sus campañas sanitarias preventivas se ha visto reflejada en el número de spots producidos por cada país en este periodo. Algunos han intentado llegar a todas las audiencias con un único relato de marcado carácter didáctico (lavado de manos, uso de mascarilla, distanciamiento social, etc.), en un intento de facilitar información a la población (ej. Nicaragua y Paraguay). Mientras, otros obvian estas narrativas elementales presentando historias más elaboradas que buscan empatizar con la audiencia juvenil (ej. México y Argentina), haciéndoles partícipes de relatos cotidianos y ligados a la cultura del visionado de series en la que están inmersos. Esta descompensación ha condicionado el presente análisis, dificultando la profundización en las narrativas de los spots de cada país en particular, así como la comparación entre países. Asimismo, la muestra española está más representada debido a que cada Comunidad Autónoma ha generado sus propios spots al tener transferidas estas competencias en materia de salud y contar con financiación para ello, a diferencia de los países latinoamericanos que mayoritariamente han centralizado estas campañas institucionales desde sus respectivos Ministerios de Salud.

\section{Referencias}

Ajzen, I. \& Fishbein, M. (2000). Attitudes and the attitude-behavior relation: Reasoned and automatic processes. European Review of Social Psychology, 11(1), 1-33. https://doi.org/10.1080/14792779943000116

Arévalo, A. (2021). Los desafíos éticos de los medios informativos en la cobertura de la Covid-19. ComHumanitas: Revista Científica de Comunicación, 11(3), 41-55. https://doi.org/10.31207/rch.v11i3.273

Arias, Y., Herrero, Y., Cabrera, Y., Guyat, D.C. \& Mederos, Y.G. (2020). Manifestaciones psicológicas frente a la situación epidemiológica causada por la COVID-19. Revista Habanera de $\begin{array}{lllll}\text { Ciencias } & \text { Médicas, } & \text { (extra } & \text { COVID-19), } & \text { e3350. }\end{array}$ http://www.revhabanera.sld.cu/index.php/rhab/article/view/3350

Bandura, A. (1990). Mechanisms of moral disengagement. En W. Reich (Ed.), Origins of Terrorism: Psychologies, Ideologies, Theologies, States of mind (pp. 161-191). Cambridge University Press.

Basch, C.E., Basch, C.H., Hillyer, G.C. \& Jaime, C. (2020a). The Role of YouTube and the Entertainment Industry in Saving Lives by Educating and Mobilizing the Public to Adopt Behaviors for Community Mitigation of COVID-19: Successive Sampling Design Study. JMIR. Public Health and Surveillance, 6(2), e19145. https://doi.org/10.2196/19145

Basch, C.H., Hillyer, G.C., Meleo-Erwin, Z.C., Jaime, C., Mohlman, J. \& Basch, C.E. (2020b). Preventive behaviors conveyed on YouTube to mitigate transmission of Covid-19: Cross-sectional study. JMIR. Public Health and Surveillance, 6(2), e18807. https://doi.org/10.2196/18807

Bruner, J. (1988). Desarrollo cognitivo y educación. Morata.

Burgos-García, A. (2019). Formación para la salud y seguridad escolar. European Journal of Health Research, 5(1), 17-30. https://doi.org/10.30552/ejhr.v5i1.134

Castello, A. \& Del-Pino, C. (2019). De la publicidad a la comunicación persuasiva integrada: estrategia y empatía. ESIC Editorial. 
Castillo-Esparcia, A., Fernández-Souto, A.B. \& Puentes-Rivera, I. (2020). Comunicación política y Covid-19. Estrategias del Gobierno de España. Profesional de la información, 29(4), e290419. https://doi.org/10.3145/epi.2020.jul.19

Cuesta, U., Menéndez, T., \& Ugarte, A. (Coords.) (2011). Comunicación y salud: nuevos escenarios y tendencias. Editorial Complutense.

Del Moral, G., Suárez, C., Moreno, D., \& Musitu, G. (2014). La música hip-hop como recurso preventivo del acoso escolar: análisis de 10 canciones de hip-hop en español sobre bullying. Qualitative Research in Education, 3(1), 1-29. http://dx.doi.org/10.4471/qre.2014.34

Eghtesadi, M. \& Florea, A. (2020). Facebook, Instagram, Reddit and TikTok: a proposal for health authorities to integrate popular social media platforms in contingency planning amid a global pandemic outbreak. Canadian Journal of Public Health, 111, 389-391. https://doi.org/10.17269/s41997-020-00343-0

Gil, M., Gómez, R. \& Almansa, A. (2020). YouTube y coronavirus: análisis del consumo de vídeos sobre la pandemia COVID-19. Revista Latina de Comunicación Social, 78, 121-153. https://doi.org/10.4185/RLCS-2020-1471

González-Casas, D., Mercado, E., Corchado, A.I., \& De la Paz-Elez, P. (2020). COVID-19 y su asociación con síntomas depresivos en la población española. Revista Habanera de Ciencias Médicas, 19(5), e3631. https://bit.ly/3boSmK7

González-Oñate, C., Vazquez-Cagiao, P. \& Farrán-Teixidó, E. (2019). Modelos de comunicación eficaces en las campañas de Publicidad. Un análisis estratégico para la búsqueda de la eficacia. Communication \& Society, 32(4), 109-124. https://doi.org/10.15581/003.32.4.109-124

Hair, J.F., Black, W.C., Babin, B.J., Anderson, R.E. \& Tatham, R.L. (2014). Multivariate Data Analysis. Pearson Education Inc.

Hermann-Acosta, A. (2020). Storytelling y comunicación multidireccional: una estrategia formativa para la era digital. URU, Revista de Comunicación y Cultura, 3, 30-43. https://doi.org/10.32719/6312514.2020.3.3

Justo-Alonso, A., García-Dantas, A., González-Vázquez, A. I., Sánchez-Martín, M. \& del RioCasanova, L. (2020). How did different generations cope with the COVID-19 pandemic? Early stages of the pandemic in Spain. Psicothema, 32(4), 490-500. http://doi.org/10.7334/psicothema2020.168

Khatri, P., Singh, S. R., Belani, N K., Yeong, Y.L., Lohan, R., Lim, Y.W. \& Teo, W.Z.Y. (2020). YouTube as source of information on 2019 novel coronavirus outbreak: a cross sectional study of English and Mandarin content. Travel medicine and infectious disease, 35, e101636. https://doi.org/10.1016/j.tmaid.2020.101636

López-Hermida, A. \& Illanes, N.I. (2013). Nuevas narrativas en Comunicación de Salud: El storytelling y la conquista emocional del paciente. Anuario Electrónico de Estudios en Comunicación Social. Disertaciones, 6(2), 47-71. https://cutt.ly/OkzdgiW 
López-Roldán, P. \& Fachelli, S. (2016). Análisis de varianza. En P. López-Roldán y S. Fachelli, Metodología de la Investigación Social Cuantitativa. Universitat Autònoma de Barcelona. http://ddd.uab.cat/record/163568

Losada, J.C., Rodríguez, L. \& Paniagua, F.J. (2020). Comunicación gubernamental y emociones en la crisis del Covid-19 en España. Revista Latina de Comunicación Social, 78, 23-40. https://doi.org/10.4185/RLCS-2020-14

Macassi, S. (2020). Comunicación para el cambio de comportamientos y estrategia sanitaria del gobierno peruano frente al COVID-19. Chasqui, Revista Latinoamericana de Comunicación, 145, 235-258. https://revistachasqui.org/index.php/chasqui/article/view/4360

Martínez, E.C. (2020). Uso de personajes y metáforas en la gestión de la crisis sanitaria del COVID19. Revisión de la comunicación de sanidad pública en España y México. Revista Española de Comunicación en Salud, 1, 319-327. https://doi.org/10.20318/recs.2020.5458

Morales, D. (2020). Análisis sociolingüístico de la publicidad. Triangle, 16, 1-53. https://doi.org/10.17345/triangle16.1-53

Muñoz, J.M. \& Segovia, B. (2019). ¿Cómo interactúan los adolescentes con los videojuegos? Preferencias y habilidades performativas. Revista Latina de Comunicación Social, 74, 360-382. https://doi.org/10.4185/RLCS-2019-1335

Orduña, E., Font, C.I. \& Ontalba, J.A. (2020). Covid-19: análisis métrico de vídeos y canales de comunicación en YouTube. Profesional de la información, 29(4), e290401. https://doi.org/10.3145/epi.2020.jul.01

Orozco, J.A. (2010). Comunicación estratégica para campañas de publicidad social. Pensar la publicidad, 4(2), 169-190. https://n9.cl/5ak3

Ortiz, M.J. (2020). Narrativa Audiovisual Aplicada a la Publicidad. Universidad de Alicante. https://cutt.ly/nxNav1v

Paredes, G. (2018). Los serious games como herramientas educo-informativas para el diseño de la conciencia social. En Torres, A. y Romero, L.M. (Eds.), Gamificación en Iberoamérica: experiencias desde la comunicación y la educación (pp. 303-331). Universidad Politécnica Salesiana. https://hdl.handle.net/11441/80681

Pérez-Moedano, K.X., Godínez-Viggiano, M.E., Hernández-Pérez, H.A. \& Ricaño-Olarte, A. (2021). Public Health at COVID times: An analysis of audiovisual campaigns. Journal of Basic and $\begin{array}{llll}\text { Applied Psychology 20-26. } & \text { 2(4), }\end{array}$ https://repository.uaeh.edu.mx/revistas/index.php/jbapr/issue/archive

Requeijo, P. \& Márquez, I. (2020). El rap como herramienta de empoderamiento y transformación social. En Sotelo, J. y Martínez, S. (Coords.) Periodismo y nuevos medios: Perspectivas y retos, (pp. 250-253). Gedisa.

Rodríguez, S.C., Cabrera, L.C. \& Calero, E. (2018). La comunicación social en salud para la prevención de enfermedades en la comunidad. Humanidades Médicas, 18(2), 384-404. http://www.humanidadesmedicas.sld.cu/index.php/hm/article/view/1302/pdf_52 
Saavedra, M., Papí, N. \& Perlado, M. (2020). Televisión y redes sociales: las audiencias sociales en la estrategia publicitaria. El profesional de la información, 29(2), e290206. https://doi.org/10.3145/epi.2020.mar.06

Sánchez-Mora, C., Aguilera, P., Hernández, M.Y. \& Patiño, M.L. (2020). Aplicación de los conocimientos científicos y la prevención de COVID-19 en México en tiempos de la posverdad. Prisma Social: revista de investigación social, 31, 82-109.

Tomba, C., Muñoz, M.C. \& Allisiardi, A.A. (2018). La responsabilidad social de la publicidad: eficacia de las campañas de bien público. Millcayac - Revista Digital de Ciencias Sociales, 5(8), 157-186. https://bit.ly/2OULOXt

Torralbas, J.E., Díaz, O. C., Gesto, F., Batista, P., García, A., Caballero, C.M., López, N. \& Escalona, A.L. (2020). Identidad nacional y percepción de riesgo ante la COVID-19 en jóvenes cubanos. Revista Cubana de Psicología, 2(2), 27-40. https://cutt.ly/ZxNpKGp

Torres, E. \& Mirón, S.G. (2020). Influencers y coronavirus. Los contenidos sobre la pandemia COVID-19 en las publicaciones de prescriptores de redes sociales en España (2020): el caso de Instagram. Quaderns del CAC, 23(46), 81-91. https://cutt.ly/zkzuasP

Valero, N.J., Vélez, M. F., Durán, Á.A. \& Torres, M. (2020). Afrontamiento del COVID-19: estrés, miedo, ansiedad y depresión. Enfermería Investiga, 5(3), 63-70. https://revistas.uta.edu.ec/erevista/index.php/enfi/article/view/913

Yañez, S. \& Cusot, G. (2018). Análisis del uso de la publicidad en las organizaciones de gobierno: información, posicionamiento y propaganda. MARCO: Marketing y Comunicación Política, 4, 3144. https://doi.org/10.15304/marco.4.5291

\section{AUTOR/ES:}

\section{Dra. María Esther del-Moral-Pérez}

Catedrática de Universidad. Imparte TIC aplicadas a la Educación. Facultad de Formación del Profesorado y Educación. Universidad de Oviedo (España). Cuenta con 4 sexenios de investigación. Coordina el Grupo de Investigación TECN@: Tecnología y Aprendizaje. Investigadora principal de Proyectos competitivos, autora de artículos de impacto en revistas prestigiosas. Áreas de Investigación: e-learning, alfabetización digital, TV e infancia, videojuegos, redes sociales, realidad aumentada, aplicaciones digitales, etc. Realizó estancias de investigación en: Calgary (Canadá), Poitiers (Francia), Friburgo (Alemania), ITD Génova (Italia). Impartió cursos en universidades iberoamericanas (Chile, México y Perú).

emoral@uniovi.es

Índice H: 31

Orcid ID: https://orcid.org/0000-0002-9143-5960

Google Scholar: https://scholar.google.es/citations?hl=es\&user=7z8E438AAAAJ

Scopus: https://www.scopus.com/authid/detail.uri?authorId=56469725900

ResearchGate: AAC-4614-2021

ResearcherID: https://www.researchgate.net/profile/Maria_Perez44/research

Academia: https://uniovi.academia.edu/MEstherDelMoral

Dialnethttps://www.researchgate.net/profile/Maria_Perez44/research 


\section{Dra. María del Carmen Bellver-Moreno}

Profesora Contratada Doctora. Facultad de Filosofía y Ciencias de la Educación. Universidad de Valencia (España). Líneas de investigación: creatividad, redes sociales y TIC y educación, adolescencia y juventud. Cuenta con 1 sexenio de investigación. Ha realizado estancias de investigación y docencia en Québec (Canadá), Florencia (Italia) y Sántarem (Portugal). Ha participado como investigadora en proyectos competitivos y en publicaciones de impacto.

m.carmen.bellver@uv.es

\section{Índice H: 13}

Orcid ID: http://orcid.org/0000-0002-7718-9652

Google Scholar: https://scholar.google.es/citations?user=Bx3SKd4AAAAJ\&hl=es

Scopus: https://www.scopus.com/authid/detail.uri?authorId=55485864100

ResearchGate ID: https://www.researchgate.net/profile/Carmen-Bellver-2

Dialnet: https://dialnet.unirioja.es/servlet/autor?codigo $=565172$

\section{Dra. Alba Patricia Guzmán-Duque}

Doctora en TI de las Organizaciones. Líder del grupo de Investigación en Ciencias Socioeconómicas y Empresariales GICSE en Colombia y docente de carrera de Administración de Empresas en cursos relacionados con el uso de Simuladores Virtuales. Áreas de Investigación: Uso de las TI en las Organizaciones y en la Educación, Innovación, Emprendimiento, Competividad, Productividad, Calidad de la Educación Superior e Investigación-Creación.

aguzman@correo.uts.edu.co

\section{Índice $\mathrm{H}: 13$}

Orcid ID: http://orcid.org/0000-0003-1704-6884

Google Scholar: https://scholar.google.com/citations?user=fFFd5L0AAAAJ\&hl=es

\section{Scopus:}

http://www.scopus.com/inward/authorDetails.url?authorID=55972862600\&partnerID=MN8TOARS

\section{ResearchGate: H-8303-2015}

ResearchGate: https://www.researchgate.net/profile/Alba-Guzman

Academia: https://unidadestecnologicasdesantander.academia.edu/AlbaPatriciaGuzmanDuque

Dialnet: $\underline{\text { https://dialnet.unirioja.es/servlet/autor?codigo }=3171570}$

\section{Nerea López-Bouzas}

Maestra de Educación Infantil por la Universidad de Oviedo. Estudiante del Máster Universitario de Investigación e Innovación en Educación Infantil y Primaria. Becaria de Colaboración con el Departamento de Ciencias de la Educación. Miembro del grupo de investigación TECN@. Líneas de investigación centradas en la integración de recursos tecnológicos en el proceso de enseñanzaaprendizaje, aplicaciones digitales, análisis de narrativas audiovisuales, etc.

UO257373@uniovi.es

\section{Índice H:}

Orcid ID: https://orcid.org/0000-0003-0753-0672

Google Scholar: https://scholar.google.es/citations?user=oa_vfPIAAAAJ\&hl=es\&oi=ao

ResearchGate: https://www.researchgate.net/profile/Nerea-Lopez-Bouzas

Dialnet: https://dialnet.unirioja.es/servlet/articulo?codigo=7612808 
RLCS, Revista Latina de Comunicación Social, 79, 23-49

[Investigación] DOI: 10.4185/RLCS-2021-1510| ISSN 1138-5820| Año 2021

\section{ANEXO}

Tabla 1. Spots españoles publicados entre 1/09/2020-10/01/2021 (consulta 10/01/2021).

\begin{tabular}{|c|c|c|c|}
\hline Spot & Datos identificación & Visionados & Likes \\
\hline 001 & $\begin{array}{l}\text { Andalucía: Concienciación jóvenes Covid-19 } \\
\text { https://www.youtube.com/watch?v=aBKA4iMbxLo }\end{array}$ & 2.355 & 8 \\
\hline 002 & $\begin{array}{l}\text { Andalucía: Concienciación jóvenes (Linares) } \\
\text { https://www.youtube.com/watch?v=7LDms_0qT_s\&feature=emb_logo }\end{array}$ & 382 & 1 \\
\hline 003 & $\begin{array}{l}\text { Andalucía: \#CumpleTuParte \#COVID-19 } \\
\text { https://www.youtube.com/watch?v=6w154egQ9oM }\end{array}$ & 39.503 & - \\
\hline 004 & Andalucía: Evita los rebrotes https://www.youtube.com/watch?v=JFacRa95FB8 & 407 & 5 \\
\hline 005 & Andalucía: Hazlo por ti, por mi por todos https://www.youtube.com/watch? $\mathrm{v}=\mathrm{gRmjmk}$ zze-w & 51 & 4 \\
\hline 006 & Andalucía: Jóvenes https://www.youtube.com/watch?v=zjEHZTgR8Zo & 25.189 & 185 \\
\hline 007 & $\begin{array}{l}\text { Andalucía: Campaña Ayto jóvenes whatsapp } \\
\text { https://www.youtube.com/watch?v=vLE7bmQV91s }\end{array}$ & 180 & 4 \\
\hline 008 & Andalucía: Lo que el Covid se llevó https://www.youtube.com/watch?v=7RAm-IX1otQ & 962 & 17 \\
\hline 009 & Andalucía: No te pilles un rebrote https://www.youtube.com/watch?v=1J6YGh3IylU & 1.962 & 23 \\
\hline 010 & Aragón: Tu responsabilidad salva vidas https://www.youtube.com/watch?v=lKlyMAIJx_w & 2860 & 27 \\
\hline 011 & $\begin{array}{l}\text { Asturias: Sigue cumpliendo las medidas de seguridad contra la COVID } \\
\text { https://www.youtube.com/watch?v=xpfKe7lfzko }\end{array}$ & 1658 & 38 \\
\hline 012 & Baleares: Campaña Nadal Govern balear https://www.youtube.com/watch?v=0p-Szykbr-w & 1198 & 23 \\
\hline 013 & $\begin{array}{l}\text { Canarias: ¿Impacto de los jóvenes en la pandemia? } \\
\text { https://www.youtube.com/watch?v=6SDzcgcVS10 }\end{array}$ & 114.704 & $1,3 \mathrm{M}$ \\
\hline 014 & $\begin{array}{l}\text { Canarias: Uso mascarilla jóvenes (cantante) } \\
\text { https://www.youtube.com/watch?v=I_HwODplAs0 }\end{array}$ & 5.642 & 134 \\
\hline 015 & Canarias: El regalo del abuelo https://www.youtube.com/watch?v=VluhRRYn uM & 285.744 & 2201 \\
\hline 016 & Canarias: La última copa https://www.youtube.com/watch?v=bA9Pc9AzzKQ & 41.499 & 290 \\
\hline 017 & $\begin{array}{l}\text { Canarias: Las } 8 \text { Islas Canarias luchan contra la COVID-19 en Navidad } \\
\text { https://www.youtube.com/watch?v=rClIqyiA2oM }\end{array}$ & 6.438 & 8 \\
\hline 018 & $\begin{array}{l}\text { Canarias: Quédate en casa, cierra la puerta a los contagios } \\
\text { https://www.youtube.com/watch?v=IW68uDZQWHQ }\end{array}$ & 32.976 & 61 \\
\hline 019 & $\begin{array}{l}\text { Canarias: Spot mascarilla } \\
\text { https://www.youtube.com/watch?v=vgOltkfSUb8\&feature=emb_logo }\end{array}$ & 2.153 & 14 \\
\hline 020 & Canarias: Tengamos fundamento https://www.youtube.com/watch?v=SGJcaRBdNyg & 6.077 & 243 \\
\hline 021 & Castilla la Mancha: Distancia social https://www.youtube.com/watch?v=ElXLcz5Zzxk & 4465 & 25 \\
\hline 022 & Castilla la Mancha: Esto no es un juego https://www.youtube.com/watch?v=Fs836p525tc & 2515 & 11 \\
\hline 023 & $\begin{array}{l}\text { Castilla y León: Campaña COVID Ayto de Burgos } \\
\text { https://www.youtube.com/watch?v=4bXvdtraPfs }\end{array}$ & 1053 & 43 \\
\hline
\end{tabular}


RLCS, Revista Latina de Comunicación Social, 79, 23-49

[Investigación] DOI: 10.4185/RLCS-2021-1510| ISSN 1138-5820| Año 2021

\begin{tabular}{|c|c|c|c|}
\hline 024 & Castilla y León: Mascarilla jóvenes https://www.youtube.com/watch?v=_dVAEUIV-o0 & 1007 & 12 \\
\hline 025 & Castilla y León: UCI https://www.youtube.com/watch?v=Bh50wzaeiOE & 59 & 0 \\
\hline 026 & Ceuta: Cómplices https://www.youtube.com/watch?v=O_SqUrfbfow & 767 & 3 \\
\hline 027 & Ceuta: Tú https://www.youtube.com/watch?v=EmK5q-WZtjw & 123 & 0 \\
\hline 028 & $\begin{array}{l}\text { Extremadura: En Navidad tú decides con quién te sientas } \\
\text { https://www.youtube.com/watch?v=6Bsa9abU4po }\end{array}$ & 79 & 3 \\
\hline 029 & Extremadura: Me comprometo, jóvenes https://www.youtube.com/watch?v=j_1nw5yBnFw & 124 & 1 \\
\hline 030 & Galicia: No vas a poder con nos https://www.youtube.com/watch?v=vSMHNejwtHM & 559.515 & 6204 \\
\hline 031 & Madrid: ¡Protégete, protégenos! https://www.youtube.com/watch?v=Q7glbAOGUVw & 76.395 & - \\
\hline 032 & Madrid: ¿Lo pillas? https://www.youtube.com/watch?v=g7DKkHx-Xd8 & 260 & 16 \\
\hline 033 & Madrid: Esta vez está en tus manos https://www.youtube.com/watch?v=zB-lmqirgXw & 50 & 2 \\
\hline 034 & Madrid: Game over https://www.youtube.com/watch?v=uOveigWoZQ8 & 10 & - \\
\hline 035 & $\begin{array}{l}\text { Madrid: Influencers: ser joven no te protege del COVID-19 } \\
\text { https://www.youtube.com/watch?v=H4h8 a2GeAk }\end{array}$ & 262 & 1 \\
\hline 036 & $\begin{array}{l}\text { Madrid: Mensaje de Navidad CA de Madrid } \\
\text { https://www.youtube.com/watch?v=EYz7-ikiAyA }\end{array}$ & 591 & 10 \\
\hline 037 & $\begin{array}{l}\text { Madrid: \#PorMíNoTeVasAContagiar } \\
\text { https://www.youtube.com/watch?v=KB19eZKL1m8 }\end{array}$ & 77.004 & 908 \\
\hline 038 & Madrid: Por mi, por todos, por ti https://www.youtube.com/watch?v=14tT4_3rurc & 2520 & 17 \\
\hline 039 & Madrid: Saltarse la cuarentena https://www.youtube.com/watch?v=DGc5wXDT3CY & 17.748 & 134 \\
\hline 040 & Madrid: $2^{\circ}$ spot: 'Protégete, protégenos' https://www.youtube.com/watch?v=Ec74p6mun6Q & 180 & 4 \\
\hline 041 & $\begin{array}{l}\text { Navarra: Jóvenes en reuniones sociales frente a la COVID-19 } \\
\text { https://www.youtube.com/watch?v=rA081OFP_rA }\end{array}$ & 8690 & 44 \\
\hline 042 & Valencia: "Si la lías, nos la lías a todos" https://acortar.link/oF7cb & 36.474 & - \\
\hline 043 & Valencia: Sé prudente https://www.youtube.com/watch?v=CWqJrav9dRs & 18.037 & 168 \\
\hline 044 & $\begin{array}{l}\text { Todas: Campaña dirigida a los jóvenes (Productora: El mundo) } \\
\text { https://www.youtube.com/watch?v=y967w609Ry8 }\end{array}$ & 32.042 & 145 \\
\hline 045 & Todas: El mejor regalo es cuidarnos https://www.youtube.com/watch?v=NJK_bHiFwGk & 22.175 & 155 \\
\hline 046 & Todas: No seas imbécil (productora) https://www.youtube.com/watch?v=QeIhYTrwuCs & 168.991 & - \\
\hline 047 & $\begin{array}{l}\text { Todas: Pito pito... esto no es un juego Ministerio Sanidad } \\
\text { https://www.youtube.com/watch?v=WOWJYEFqtQ8 }\end{array}$ & 98.554 & $1 \mathrm{M}$ \\
\hline 048 & País Vasco: Hospital https://youtu.be/8Hy45ksD1Ws & 2.388 & 11 \\
\hline 049 & Ceuta: Jóvenes https://youtu.be/yHUsigBXPwA & 252 & 3 \\
\hline 050 & Cataluña: Cantantes https://www.youtube.com/watch?v=YcDEur1IxCs & 552.839 & 8579 \\
\hline
\end{tabular}

Fuente: Elaboración propia 
RLCS, Revista Latina de Comunicación Social, 79, 23-49

[Investigación] DOI: 10.4185/RLCS-2021-1510| ISSN 1138-5820| Año 2021

Tabla 2. Spots latinoamericanos publicados entre 1/09/2020-10/01/2021 (consultados 10/01/2021)

\begin{tabular}{|c|c|c|c|}
\hline Spot & Datos de identificación & Visionados & Like \\
\hline 051 & Argentina: Evitemos las reuniones https://www.youtube.com/watch?v=PDK5BFgnO88 & 6469 & 62 \\
\hline 052 & $\begin{array}{l}\text { Argentina: Historia real de un paciente por Fabián Vena } \\
\text { https://www.youtube.com/watch?v=HmzkkgDkZdE }\end{array}$ & 3.952 & 46 \\
\hline 053 & $\begin{array}{l}\text { Argentina: Diego Maradona y Víctor Hugo Morales: evitar contagios } \\
\text { https://www.youtube.com/watch?v=Up_Yxodm-Lk }\end{array}$ & 5.616 & 92 \\
\hline 054 & Argentina: El virus avanza https://www.youtube.com/watch?v=ueKjg3OzSRY & 538.276 & 115 \\
\hline 055 & $\begin{array}{l}\text { Argentina: Festejemos con responsabilidad } \\
\text { https://www.youtube.com/watch?v=9y1P9CGqQhY }\end{array}$ & 210 & 1 \\
\hline 056 & Argentina: Fiestas clandestinas https://www.youtube.com/watch?v=eKCHOSjJ874 & 2.846 & 49 \\
\hline 057 & $\begin{array}{l}\text { Argentina: Historia real de una paciente } 30 \\
\text { https://www.youtube.com/watch?v=dohV11EJLW4 }\end{array}$ & 4.288 & 38 \\
\hline 058 & $\begin{array}{l}\text { Argentina: Historia real de una paciente } 50 \\
\text { https://www.youtube.com/watch?v=e13tbiaOZlk }\end{array}$ & 3.092 & 35 \\
\hline 059 & $\begin{array}{l}\text { Argentina: La cuidadanía Gobierno Nacional } 2^{\mathrm{a}} \text { ola } \\
\text { https://www.youtube.com/watch?v=DioKZr3MOWc }\end{array}$ & 1.416 & 10 \\
\hline 060 & Argentina: No hay otra https://www.youtube.com/watch?v=mGFiCLJ4YbA & 208.419 & 154 \\
\hline 061 & $\begin{array}{l}\text { Argentina: Nadie sale sale campeón solo (Maradona) } \\
\text { https://www.youtube.com/watch?v=RNJ7VMUR_D4 }\end{array}$ & 36.855 & 700 \\
\hline 062 & $\begin{array}{l}\text { Brasil: Spot Prevenção \& Sintomas | IMVF | COVID-19 São Tomé e Príncipe } \\
\text { https://www.youtube.com/watch?v=1u0yo8cB2ig }\end{array}$ & 714 & 3 \\
\hline 063 & $\begin{array}{l}\text { Brasil: Minuto Saúde - Prevenção coronavírus } \\
\text { https://www.youtube.com/watch?v=aQCnF1yY7Uc }\end{array}$ & 130.731 & 1878 \\
\hline 064 & Chile: No expongas a nadie https://www.youtube.com/watch?v=WZd-FA9NZVQ & 494 & 2 \\
\hline 065 & Chile: Cuidémonos entre todos https://www.youtube.com/watch?v=xsk8VS5EsR4 & 180.773 & 703 \\
\hline 066 & $\begin{array}{l}\text { Chile: Esta pandemia la superaremos entre todos } \\
\text { https://www.youtube.com/watch?v=XBoFJp_rbYQ }\end{array}$ & 56.457 & 969 \\
\hline 067 & Colombia: No hay excusas https://www.youtube.com/watch?v=TqyPIB6bn7Q & 5.386 & 45 \\
\hline 068 & Colombia: Coronavirus en 4 enero 2021 https://www.youtube.com/watch?v=xkR_0En_iaU & 345.453 & 228 \\
\hline 069 & $\begin{array}{l}\text { Colombia: Todos estamos unidos frente al COVID } \\
\text { https://www.youtube.com/watch?v=1PDlrRzg208 }\end{array}$ & 163 & 2 \\
\hline 070 & Costa Rica: Cuidate https://www.youtube.com/watch?v=OTEsemTG0BQ & 449 & 3 \\
\hline 071 & Costa Rica: Dña. Merry https://www.youtube.com/watch?v=YbEkkDVYvJc & 195 & 4 \\
\hline 072 & Costa Rica: Personas mayores https://www.youtube.com/watch?v=LmK0oZ9gkB4 & 209 & 1 \\
\hline 073 & Cuba: Mi taller Spot Covid https://www.youtube.com/watch?v=A0BEMDw7NhQ & 46 & 0 \\
\hline
\end{tabular}


RLCS, Revista Latina de Comunicación Social, 79, 23-49

[Investigación] DOI: 10.4185/RLCS-2021-1510| ISSN 1138-5820| Año 2021

\begin{tabular}{|c|c|c|c|}
\hline 074 & Ecuador: Yo me cuido https://www.youtube.com/watch?v=mqysWZ9nt30 & 154 & 4 \\
\hline 075 & Ecuador: Pautas higiene https://www.youtube.com/watch?v=zLSvntqSelg & 27 & 0 \\
\hline 076 & Honduras: Navidad sin Covid https://www.youtube.com/watch?v=8s-nftkPCBk & 13 & 2 \\
\hline 077 & México: Adultos mayores https://www.youtube.com/watch?v=hs4HvlEriwQ & 64.487 & 444 \\
\hline 078 & México: Debemos de tomar conciencia https://www.youtube.com/watch?v=_DDo3OpLDik & 76 & 5 \\
\hline 079 & México: Festa de muerte https://www.youtube.com/watch?v=eDktQZotr5Q & 19 & 0 \\
\hline 080 & México: Sana distancia 1 https://www.youtube.com/watch?v=qRN7P7djrp0 & 27.059 & 311 \\
\hline 081 & México: Sana distancia 2 https://www.youtube.com/watch?v=CbR8SVJPf8c & 29.412 & 503 \\
\hline 082 & México: SIMNSA contra el COVID-19 https://www.youtube.com/watch?v=17I0Sd2FrL0 & 373 & 8 \\
\hline 083 & México: Susana distancia https://www.youtube.com/watch?v=tD0kClwV3O4 & 20.672 & 59 \\
\hline 084 & México: Susana distancia, animación https://www.youtube.com/watch?v=Zd6dP3HfbFU & 46.189 & 299 \\
\hline 085 & Nicaragua: Mantengamos distancia https://www.youtube.com/watch?v=cz13Fqxrm6o & 74 & 2 \\
\hline 086 & Nicaragua: Universitarios https://www.youtube.com/watch?v=iDaX-sVS5Yc & 761 & 60 \\
\hline 087 & Paraguay: Sanitarios https://www.youtube.com/watch?v=RikW0g39pqo & 2.452 & - \\
\hline 088 & Perú: El Covid no mata solo 1 https://www.youtube.com/watch?v=06SfIbGVaAM & 1.922 & 28 \\
\hline 089 & Perú: No bajemos la guardia 1 https://www.youtube.com/watch?v=2d9RutAkaG4 & 252 & 3 \\
\hline 090 & Perú: No bajemos la guardia 2 https://www.youtube.com/watch?v=9ZcurMhSk8w & 1.167 & 13 \\
\hline 091 & Perú: El Covid no mata solo 2 https://www.youtube.com/watch?v=cVlfK_Mtt0 & 9.520 & 153 \\
\hline 092 & $\begin{array}{l}\text { Perú: Coronavirus (normas prevención) } \\
\text { https://www.youtube.com/watch?v=wyjU2xVXm4A }\end{array}$ & 33.878 & 128 \\
\hline 093 & Perú: Protege a tus mayores https://www.youtube.com/watch?v=erajdHQGMfg & 1.348 & 11 \\
\hline 094 & Puerto Rico: Protección Navidad https://www.youtube.com/watch?v=IJRKfOduLo0 & 1.238 & 23 \\
\hline 095 & Puerto Rico: Pandemio \& Covidia https://www.youtube.com/watch?v=8SLZ08M0mkQ & 232 & 5 \\
\hline 096 & Puerto Rico: Se busca https://www.youtube.com/watch?v=xvL0UsBWhmw & 203 & 5 \\
\hline 097 & Puerto Rico: Sobrino COVID https://www.youtube.com/watch?v=_y5OGfcNSjo & 127 & 3 \\
\hline 098 & Salvador: Medidas básicas https://www.youtube.com/watch?v=he9e2eR1Vh0 & 242 & 5 \\
\hline 099 & $\begin{array}{l}\text { Uruguay: Campaña Presidencia República "2 metros" } \\
\text { https://www.youtube.com/watch?v=HNCH-AGvtYM }\end{array}$ & 5.868 & 72 \\
\hline 100 & Uruguay: Recomendaciones https://www.youtube.com/watch?v=pkZ3_JRC2xk & 32 & 1 \\
\hline
\end{tabular}

Fuente: Elaboración propia 